\title{
Narratives in entrepreneurial ecosystems: drivers of effectuation versus causation
}

\author{
Sylvia Hubner (D) Fabian Most · Jochen Wirtz • \\ Christine Auer
}

Accepted: 18 June 2021 / Published online: 2 August 2021

(C) The Author(s) 2021

\begin{abstract}
This paper introduces narratives in entrepreneurial ecosystems as drivers of effectuation vs. causation. Drawing on 43 interviews with successful players in Silicon Valley, Munich, and Singapore, we found ecosystem-specific narratives indicate what is common, appropriate, and successful in each ecosystem, and these narratives encourage either effectuation or causation. Our findings indicate that the narratives in the ecosystem in Silicon Valley facilitate effectuation, in Munich causation, and in Singapore a cautious balance of both. Our research suggests that narratives can explain mechanisms how ecosystems influence entrepreneurship: the national culture, market characteristics, available resources, and networks in an ecosystem spark ecosystem-specific narratives, which in turn shape tendencies towards effectuation and causation. Thereby, we introduce a new ecosystem-focused perspective on predictors of effectuation and causation.
\end{abstract}

\section{S. Hubner $(\square)$}

Free University of Bozen-Bolzano, Bolzano, Italy

e-mail: sylvia.hubner@unibz.it

F. Most

Ginkgo Management Consulting, Singapore, Singapore

J. Wirtz

National University of Singapore, Singapore, Singapore

C. Auer

Ludwig-Maximilians-University Munich, Munich,

Germany
Plain English Summary The ecosystems in Silicon Valley, Munich, and Singapore spark different narratives about entrepreneurship, which indicate what is common, appropriate, and successful in the ecosystem and in turn encourage different kinds of entrepreneurial approaches. We conducted 43 interviews with successful players in Silicon Valley, Munich, and Singapore. We found ecosystem-specific narratives indicate what is common, appropriate, and successful in an ecosystem and encourage different kinds of entrepreneurial behavior and decision-making. Those narratives seem to shape tendencies towards specific strategic logics. The narratives either encourage "effectuation" (i.e., when they focus on building partnerships and utilizing the networks, and when they encourage confidence and speed) or "causation" (i.e., when they focus on developing systematics and structured plans, and when they encourage harmony and conformity). Narratives in Silicon Valley seem to facilitate effectuation, in Munich causation, and in Singapore both. Our research suggests that narratives explain mechanisms how ecosystems influence entrepreneurship: the national culture, market characteristics, available resources, and networks in an ecosystem spark ecosystem-specific narratives, which in turn shape tendencies towards effectuation and causation. Thereby, we introduce a new ecosystem-focused perspective on predictors of effectuation and causation. Our findings suggest specific strategies and success factors in each ecosystem. For example, the narratives prevalent in Silicon Valley have a sales focus, 
in Munich a need for detailed plans, and in Singapore value conformity. Thus, our findings provide insights for entrepreneurs for strategic location choices and on how to position their new venture at a specific location. VCs and policy makers gain from insights into how to leverage strengths and how to counteract problematic mechanisms in an ecosystem.

Keywords Ecosystems - Effectuation - Causation · Narratives · Silicon Valley · Munich · Singapore · Entrepreneurship · Entrepreneurial behavior . Culture $\cdot$ Networks

\section{JEL Classifications $\quad \mathrm{A} 13 \cdot \mathrm{M} 16 \cdot \mathrm{L} 26 \cdot \mathrm{O} 30 \cdot \mathrm{O} 31$}

\section{Introduction}

Entrepreneurs' attitudes, decisions, and actions in the processes of idea generation and refining, experimenting, resource acquisition, and network building are influenced by environmental factors such as the national culture at their location, characteristics of the industry, and the availability of resources (Hayton et al., 2002; Laskovaia et al., 2017). Such environmental factors combine to specific factor constellations in entrepreneurial ecosystems (Spigel \& Harrison, 2018). Entrepreneurial ecosystems are cohesive regional communities of entrepreneurs and their supporters (Spigel \& Harrison, 2018). Previous entrepreneurship research has mainly neglected the locale, ecosystem-specific interplay of factors influencing entrepreneurship, due to a focus on analyses of one or few influence factors in isolation. Nevertheless, research on entrepreneurial ecosystems shows that the factor constellation in an ecosystem determines the nature of entrepreneurial activity. In particular, factors can reinforce or counterbalance each other as they influence the flow of resources, available knowledge, and attitudes within the community (Spigel, 2017; Spigel \& Harrison, 2018). This stream of research on ecosystems, however, focused on analyzing the characteristics, development, economic output, and regional outcomes of ecosystems (Wurth et al., 2021). The mechanisms how ecosystems influence entrepreneurship remain under-theorized (Roundy \& Fayard, 2019; Spigel \& Harrison, 2018; Wurth et al., 2021).
In this paper, we illuminate how ecosystems influence the behavior and decision-making of entrepreneurs. We suggest that certain factor constellations in an ecosystem spark specific narratives about entrepreneurial activity. As part of the local entrepreneurial culture, narratives take hold in an ecosystem, for example, via entrepreneurs' success stories and recommendations of stakeholders (Roundy \& Bayer, 2019). Such narratives indicate what kind of entrepreneurial attitudes, decisions, and actions are considered common, appropriate, and successful in an ecosystem, and therefore influence entrepreneurial behavior and decision-making. We suggest ecosystem-specific narratives can influence tendencies towards either effectuation or causation (Sarasvathy, 2001, 2009).

The effectuation literature holds that individuals make decisions in accordance with characteristics of their situation (Sarasvathy, 2001). Specifically, effectuation has been suggested as a strategic decision making logic that can address the uncertainty and unpredictability in entrepreneurship (Sarasvathy, 2001). When applying effectuation, entrepreneurs aim at controlling instead of predicting the future, think in a dynamic and nonlinear process, start their actions based on their means at hand, and focus on building partnerships with stakeholders. In contrast, when applying causation, they focus on a specific and fixed goal, think in a linear process, and rely on prediction to address competition. Previous effectuation literature suggests that individual level factors (Frese et al., 2019; Gabrielsson \& Politis, 2011; Harms \& Schiele, 2012; Markowska et al., 2018) and also environmental factors (e.g., Frese et al., 2019; Laskovaia et al., 2017; Read \& Sarasvathy, 2005) influence choices for either effectuation or causation. However, this research neglected that these influence factors play together and that this interplay may vary across different locations. We investigate how and why factor constellations in ecosystems influence tendencies towards effectuation vs. causation.

Our investigation draws on 43 qualitative interviews with successful serial entrepreneurs, business angels, VCs, and heads of accelerators and incubator programs, who have experiences in the entrepreneurial ecosystems in Silicon Valley, Munich, and/or Singapore. Silicon Valley is particularly interesting because it is repeatedly highlighted as a 
prototype entrepreneurial ecosystem (Gill \& Larson, 2014). Although the situation regarding the national culture, attitudes towards entrepreneurship, and the education and law system appear less favorable for entrepreneurship in Munich and Singapore, Munich is among the largest and strongest entrepreneurial ecosystems in Europe, and Singapore is among the strongest environments for entrepreneurs in Asia (Bosma et al., 2020; House et al., 2004; Schönenberger, 2014; Xavier et al., 2016). Thus, all three ecosystems can be considered successful in their geography-but they might facilitate entrepreneurship in different ways (Whittaker, 2009; Wurth et al., 2021). Our analysis identifies specific factor constellations in those ecosystems, analyzes how the specific factor constellations relate to certain narratives about what is common, appropriate, and successful in those ecosystems, and investigates how those narratives relate to effectuation and causation.

Our research contributes to the literature in several ways. First, we illuminate mechanisms of how ecosystems influence entrepreneurship. Our research indicates that the national culture, market characteristics, available resources, and networks spark ecosystem-specific narratives which in turn shape tendencies towards effectuation or causation. These findings provide knowledge on the mechanisms of how ecosystem characteristics influence entrepreneurs' behaviors and decision-making. Second, we introduce differences in factor constellations in entrepreneurial ecosystems as drivers of effectuation and causation. Our findings illuminate in what way characteristics of the local environment shape entrepreneurs' tendencies towards effectuation or causation and explain why some ecosystems encourage and facilitate effectuation more than others. Thus, we introduce a new ecosystem-focused perspective on predictors of effectuation and causation. Third, as we suggest ecosystem-specific narratives connect ecosystem characteristics and effectuation, we bridge the ecosystem and effectuation literature. Connecting findings of the ecosystem literature with findings of the effectuation literature, we provide a more comprehensive picture than each of the literatures can provide. Finally, our analysis of effectuation and causation in different ecosystems provides insights into the suitability of effectuation and causation in different contexts.

Knowledge about ecosystem-specific mechanisms will help entrepreneurs strategically choose a location, develop strategies that fit their environment, leverage location-specific success factors, and decide whether to position their new venture against or in compliance with the norms and values in their ecosystem. Understanding the commonalities and differences of ecosystems can also help entrepreneurs identify and leverage best practices across different ecosystems while still focusing on the specifics of an ecosystem. Moreover, knowledge about ecosystemspecifics and their potential causes and effects can inform venture capitalists and policy makers how to support entrepreneurs in different locations, and how to leverage strengths and counteract problematic mechanisms to advance an ecosystem.

\section{Theoretical background}

Entrepreneurial action is a response to a possible opportunity for profit under perceived uncertainty (McMullen \& Shepherd, 2006). The uncertainty in entrepreneurial actions complicates predictions of consequences of decisions and in turn complicates any kind of planning. Entrepreneurial actions therefore require distinguished forms of decision-making (Alvarez \& Barney, 2005; Busenitz \& Barney, 1997; Engel et al., 2014). In the following, we first introduce the decision-making logics of effectuation and causation, and then discuss how ecosystem differences might, via specific narratives, encourage or hinder one logic or the other.

\subsection{Effectuation and causation}

Effectuation has been suggested as a strategic decision-making logic which can address the uncertainty in entrepreneurial efforts (Sarasvathy, 2001). Effectuation relies on control instead of prediction and works in a dynamic and nonlinear process. Effectuation usually is described in contrast to causation. This contrast can be pinpointed along four dimensions (Brettel et al., 2012; Sarasvathy, 2001, 2009): (1) effectuation sees contingencies as opportunities that should be 
leveraged rather than avoided, whereas causation processes try to predict the future as accurately as possible to avoid unexpected contingencies. (2) Effectuation starts with the means at hand including the entrepreneur's identity (who I am), knowledge (what I know), and networks (who I know) and considers all possible effects. Causation, by contrast, starts with the definition of a predefined goal (what I should do). (3) Effectuation focuses on minimizing risk by considering the maximum affordable loss, whereas causation focuses on maximizing expected returns. (4) Effectuation aims at establishing pre-commitments with potential partners, with a focus on building alliances. Causation models, by contrast, analyze the market and focus on competition. Thereby, causation suggests planned strategy approaches, whereas effectuation incorporates flexibility and experimentation (Chandler et al., 2011). Importantly, effectuation and causation can be used in combination (Reymen et al., 2015; Smolka et al., 2018).

Depending on contextual factors, such as resource availability or the firm's development stage, either causation or effectuation appears particularly useful (An et al., 2020; Berends et al., 2014; Read \& Sarasvathy, 2005; Sarasvathy, 2001). Causation forms the basis for several tools and procedures which support business decisions (Smolka et al., 2018). Effectuation, because of its control-based and flexible decision-making approaches, has been suggested to be particularly advantageous in dynamic, uncertain and resource-constrained environments, which are common in entrepreneurship (Alvarez \& Barney, 2005; Mauer et al., 2018; Read et al., 2009; Roach et al., 2016; Wiltbank et al., 2009).

Recently, more and more studies investigated why entrepreneurs tend to apply either effectuation or causation. Individual, team, organizational, and environmental factors can influence decisions for effectuation vs. causation. Influences on the individual level suggest entrepreneurs are more likely to rely on effectuation when they are frugal and have (harmonious) passion for the product, and have social aspirations; in contrast, they are more likely to rely on causation when they have high self-control, passion for growth, and commercial aspirations (Cannatelli et al., 2019; Liu, 2019; Michaelis et al., 2020; Stroe et al., 2018). Moreover, Frese et al. (2019) found entrepreneurs' management and entrepreneurial experience foster effectuation. In contrast, Markowska et al. (2018) found that work and founding experience foster causation. Engel et al. (2013) suggest an influence of career experiences. Interestingly, the influence of psychological factors seems to differ across countries (Zhang et al., 2019), and the influence of experience seems to be stronger in earlier than later stages of venture development (Frese et al., 2019).

On the team or project level, the relations within the team (Tryba \& Fletcher, 2019) and the intensity of planning and monitoring (Nguyen et al., 2018) can influence whether effectuation or causation is applied. On the organizational level, the service intensity of the firm (Cui et al., 2019) and its organizational culture and structure (Henninger et al., 2020) can influence a focus on effectuation vs. causation. Also, the environment and actors in the environment can have an influence: investors (Frese et al., 2019), business and institutional ties (Zhang et al., 2020), and the national culture (Laskovaia et al., 2017) have been shown to influence preferences for effectuation or causation. Importantly, disruptive events can change preferences for one logic over the other (Nelson \& Lima, 2019). In sum, there is a complex interplay of different factors on different levels (Johansson \& McKelvie, 2012). We argue that the interplay of influence factors varies across locations and suggest there are ecosystem-specific influence mechanisms, via ecosystem-specific narratives.

\subsection{Narratives in entrepreneurial ecosystems}

Roundy and Bayer (2019) suggest that narratives, which take hold in success stories and prevalent recommendations in an ecosystem, influence entrepreneurs' actions, and might even be an explanation for ecosystem success. Narratives signal reasons for entrepreneurship, inspire to engage in entrepreneurship, increase the legitimacy of entrepreneurship (Isenberg, 2010), and can influence performance by shaping perceptions of success and failure (Wolfe \& Shepherd, 2015). Gill and Larson (2014) show entrepreneurial narratives can be linked to specific locations and to particularities of a region. The most adequate storytelling and symbolism thus may differ at different locations. To reach legitimacy, entrepreneurs need to choose their storytelling and actions in accordance with expectations of the local environment (De Clercq \& Voronov, 2009; Fisher et al., 2016). Ecosystem-specific narratives can be 
influenced by the environment and the actors in the ecosystem.

An entrepreneurial ecosystem is characterized by self-governance (Isenberg, 2016; Roundy et al., 2018) and refers to the people, institutions, policies, and resources that promote the translation of new ideas into products, processes, and services at a specific location (Bhawe \& Zahra, 2019). Actors in entrepreneurial ecosystems contain entrepreneurs, angel investors, incubators, and other actors such as customers, suppliers, venture capitalists, research centers, universities, and governments (Audretsch \& Link, 2019). Whereas most entrepreneurial ecosystems share several goals and typical actors, they differ in their composition and dynamics (Bhawe \& Zahra, 2019; Spigel, 2017). There is both a top-down approach, where one or more parties initiate the development of an ecosystem and shape goals and constraints (Nambisan \& Baron, 2013); and a bottom-up approach, where ecosystems evolve over time like natural ecosystems influenced by mechanisms of selection and self-selection (Bertoni et al., 2019; Colombo et al., 2019). In either case, many non-linear dynamics may play together. Spigel (2017) show that material, social, and cultural attributes of entrepreneurial ecosystems create and reinforce possibilities and behaviors of entrepreneurs. So far, however, the influence of entrepreneurial ecosystems on entrepreneurs is still under-theorized (Roundy \& Fayard, 2019; Spigel \& Harrison, 2018).

Literature on entrepreneurial ecosystems is mainly focused on analyzing the characteristics, development, economic output, and regional outcomes of ecosystems (Wurth et al., 2021) such that the mechanisms of how an ecosystem influences entrepreneurship remain unclear. Particularly, this research stream neglected the influence of ecosystem characteristics on entrepreneurs' individual behaviors and decisionmaking. In an ecosystem, factors that foster or hinder particular behaviors or decision-making of entrepreneurs, for example, either effectuation or causation, can reinforce or counterbalance each other. Uncovering such mechanisms is possible in analyses that consider influences of the ecosystem as a whole and the interplay of a wide range of influence factors. Such analyses can provide a comprehensive understanding of ecosystem-specific influence mechanisms.

We suggest that ecosystem-specific factor constellations drive ecosystem-specific narratives which create and reinforce tendencies towards specific entrepreneurial approaches. Narratives indicate which approaches are considered common, useful, appropriate, and/or successful in an ecosystem. Prominent and reiterated narratives create an impression that following the narrative is necessary, regardless of whether or not this approach actually is more efficient. Because narratives vary across ecosystems (Gill \& Larson, 2014), different ecosystems may shape tendencies towards different approaches. We suggest ecosystems create and reinforce tendencies towards either effectuation or causation. In the following, we discuss findings of previous literatures which indicate how ecosystem specifics, and ecosystem-specific narratives, might relate to effectuation or causation. We elaborate on influences of the "national culture and attitudes" referring to individual psychological pre-dispositions of people in the country of the ecosystem, "market characteristics" referring to locale/ city-specific market attributes such as its dynamism, "available resources" referring to the resources that are potentially available to entrepreneurs in the ecosystem, and "networks" referring to the local networks and partners that entrepreneurs in the ecosystem can reach out to. We discuss those influence factors because they emerged to be relevant during the analysis of our empirical data.

\subsubsection{National culture and attitudes}

Previous research shows that the national culture, such as the level of uncertainty avoidance (Brinckmann et al., 2010; Shane, 1993), and major institutions influence predominant attitudes towards entrepreneurship and entrepreneurial actions and decisions (Baumol \& Strom, 2008; Estrin et al., 2013; Fritsch \& Storey, 2014). National culture relates to effectuation and causation (e.g., EstradaCruz et al., 2019; Laskovaia et al., 2017), for example because entrepreneurs with high levels of uncertainty avoidance are cautious and shy away from risky attempts (McMullen \& Shepherd, 2006). Those entrepreneurs are likely to engage in planning and prediction (Brinckmann et al., 2010), a logic that is part of causation. National culture also influences the perceptions of the value and risk of entrepreneurship, whether or not leaving a stable employment for entrepreneurship is encouraged (Fritsch \& Schroeter, 2011), and in 
what way entrepreneurial role models share their success stories (Wyrwich et al., 2016). That way, culture also influences career motives, which have been shown to influence preferences for effectuation or causation. That is, entrepreneurs who identify with spiral or transitory career motives prefer effectuation, whereas entrepreneurs who identify with linear or expert career motives prefer causation (Gabrielsson \& Politis, 2011). Moreover, Laskovaia et al. (2017) found performance increases via causation in a performance-based culture, and via effectuation in a socially supportive culture.

\subsubsection{Market}

Entrepreneurship also is influenced by the richness of opportunities, growth and renewal, and the hostility and rivalry in the market (Tsai et al., 1991). These attributes determine an ecosystems' dynamism and uncertainty. To address the uncertainty in an ecosystem, de Vasconcelos Gomes et al. (2018) highlight the importance of planning, an approach based on causation. In contrast, other researchers found that high uncertainty (Frese et al., 2019) and dynamism (Markowska et al., 2018) perceptions decrease causation and increase effectuation. Moreover, effectuation has been suggested as a promising approach to internationalization, particularly for entrepreneurs in unstable environments (Kujala \& Tornroos, 2018). Welter and Kim (2018) also found that effectuation outperforms causation in uncertain and risky environments and suggest effectuation as preferable whenever entrepreneurs cannot accurately predict the future. Thus, effectuation might be more prominent in dynamic and uncertain environments.

\subsubsection{Resources}

Mobilizing and transforming resources is key to entrepreneurial success (Björklund \& Krueger, 2016; Clough et al., 2019) and is influenced by dynamics in ecosystems (Bertoni et al., 2019). Resource building can be related to effectuation because effectuation focuses on mobilizing resources, e.g., via building partnerships. Indeed, effectuation has been suggested to be more appropriate under resource constraints, whereas causation is suggested to be preferable when a lot of resources are available (Read \& Sarasvathy,
2005). Thus, resource constraints might lead to a focus on effectuation whereas high resource availability might facilitate causation.

\subsubsection{Networks}

How resources are used and allocated in an ecosystem is determined by networks. Networks enable to connect with investors (Powell et al., 2002), talent (Moser et al., 2017), and with other entrepreneurs (Aldrich \& Yang, 2014). Networks support the circulation of knowledge (Hoang \& Antoncic, 2003) and allow entrepreneurs to learn from each other (Aldrich $\&$ Yang, 2014). The presence of stakeholders including universities (Maresova et al., 2019), cooperative banks (Ghio et al., 2019), and multi-national companies (MNCs) (Bhawe \& Zahra, 2019) can increase networking possibilities.

Whether or not networks leverage and facilitate effectuation is influenced by inter-relations between the structure and dynamics in the network (Galkina \& Atkova, 2020). While business ties increase the use of effectuation, institutional ties increase the use of causation (Zhang et al., 2020). Additionally, which recommendations are prominent in an ecosystem is likely to depend on the educational background of key actors in support organizations. Supporting activities (e.g., training) can be offered by universities, organizations like incubators or accelerators, or specialized firms that focus on start-up needs (Isenberg, 2010; Motoyama \& Knowlton, 2016; Shankar \& Shepherd, 2019). When expert entrepreneurs support and consult novice entrepreneurs, they might encourage effectuation (Sarasvathy, 2009). In contrast, when most entrepreneurs are taught in a business school in (non-entrepreneurial) business planning, they may be inclined to focus on causation. In general, although networking activities can build on both effectuation and causation (Galkina \& LundgrenHenriksson, 2017), entrepreneurs in ecosystems with dense networks can leverage social ties more easily (Stuart \& Sorenson, 2003). Therefore, ecosystems with dense networks might emphasize building partnerships, open exchange, and flexible networking as key to success, which relates to effectuation.

All those mechanisms, which are influenced by the national culture, market characteristics, available resources, and networks, can over time imprint narratives, which indicate what is common, useful, 
appropriate, and/or successful in an ecosystem (Baker $\&$ Welter, 2020). Based on our empirical findings, we argue that such ecosystem-specific mechanisms create and reinforce tendencies towards either effectuation or causation.

\subsection{Entrepreneurship in three different ecosystems}

Our study focuses on Silicon Valley, Munich, and Singapore. Those three ecosystems are interesting comparisons because they are geographically spread across three different continents, culturally diverse, and based in diverse domestic markets of different sizes. Still, they are comparable because they are in similarly developed economies, and (in their geography) in a comparably large city with high-ranked universities and similar compositions in terms of industries, and industry age and size (Engelen et al., 2009).

We specifically chose Silicon Valley because it is repeatedly highlighted as a prototype entrepreneurial ecosystem (Gill \& Larson, 2014). Gill and Larson (2014) argue that Silicon Valley offers an image of an "ideal" entrepreneur with which entrepreneurs across the USA, and probably around the world, are encouraged to identify. They describe Silicon Valley to have a start-up and networking culture which encourages technological innovation and risk-taking, and find that product development is driven by customer inclinations and entrepreneurs' all-encompassing work (Gill \& Larson, 2014). Silicon Valley is a "bottom-up" ecosystem, which can benefit from path dependencies and a specific culture that coordinates and motivates its members (Colombo et al., 2019). In the Silicon Valley ecosystem, universities, industrial research centers, venture capital, serial entrepreneurs, mature corporations, service providers, and the government seem to play together to create a highly successful ecosystem. Norms, rules, and behaviors appear to "naturally" select and positively influence the performance, the existence, and survival of the entrepreneurial ecosystem (Colombo et al., 2019).

The ecosystems in Munich and Singapore serve as contrasts to Silicon Valley because the situation has been portrayed to be similarly successful but different (Klandt, 2004; Lee \& Lim, 2004; Tan, 2003). In studies on national culture (GLOBE study, House et al., 2004), Singapore and Germany have been shown to score high in uncertainty avoidance, especially compared to the USA. Furthermore, Germany was portrayed as perfectionist (Aly \& Galal-Edeen, 2020) and failure is less accepted in the societies in Germany and Singapore than in the USA, which may hinder entrepreneurial activity (Bosma \& Kelley, 2019). In Singapore, the education system is less encouraging for entrepreneurial activity. For a long time, rote learning had been more important than creativity (Tan, 2003). Strategic approaches in Singapore's small businesses appear to be relatively conservative (Lee \& Lim, 2004). In Singapore, also the bankruptcy laws are comparatively unfriendly to entrepreneurs, which means bankruptcy is more painful than in other countries (Peng et al., 2010). Moreover, while Munich can be portrayed as a bottom-up ecosystem which is evolving influenced by numerous players and mechanisms of selection and self-selection (Bertoni et al., 2019; Colombo et al., 2019), Singapore can be characterized as a top-down ecosystem with a strong government influence.

The Global Entrepreneurship Monitor, a repeated comparative study on entrepreneurship across the globe (e.g., Bosma, \& Kelley, 2019; Chernyshenko et al., 2015), shows an ambiguous picture. Suggesting a contrast in attitudes towards entrepreneurship (data about Germany and the USA available from 2018, and about Singapore from 2014), the GEM data shows that in the USA, $79 \%$ of the population believe that successful entrepreneurs receive high status in the local society, in Germany its $75 \%$, and in Singapore $63 \%$. The reason for starting a business is more than six times more often a perceived opportunity than a necessity in Singapore and the USA, but only three times more often a perceived opportunity than a necessity in Germany, suggesting more necessitydriven entrepreneurship in Germany. In the USA, 63\% believe that entrepreneurship is a good career choice, whereas 52\% in Singapore and 50\% in Germany believe in entrepreneurship as a good career choice. Interestingly, however, the percentage of participants naming fear of failure as reason for staying away from starting a business was very low in Germany $(35 \%$, like in the USA) and also in Singapore (39.4\%, a figure also among the lowest compared to the other 24 countries). When comparing different regions in Germany, entrepreneurship appears to be more valued in Munich than in most other regions (Sternberg \& Litzenberger, 2004). Munich has become a large ecosystem portrayed as a knowledge factory for start-ups (Schönenberger, 2014). Singapore was ranked No.1 in 
ease of doing business in Asia (Xavier et al., 2016). Thus, Munich and Singapore have developed successful entrepreneurial ecosystems, despite the abovedescribed hindrances.

Despite this knowledge about Silicon Valley, Munich, and Singapore, in how far entrepreneurs think and act differently in these ecosystems, and how the ecosystems influence these differences is unclear. Our research attempts to fill this void.

\section{Method and analysis}

This study follows an exploratory, qualitative research design (Gioia et al., 2013; Maxwell, 2012), which appeared particularly suitable for investigating the unstructured and complex relationships in the meanings, contexts, and processes of dynamics across ecosystems. In an inductive process of analyzing interviews, we aimed to identify particularities and specifics of the ecosystems. Importantly, with this approach, we cannot infer or test causality between the concepts. Our aim was to identify concepts that are specific for each ecosystem and interpret how these concepts play together. Details about the methodological approach are outlined in the appendix.

\subsection{Sample}

Applying a theoretical sampling strategy (Eisenhardt et al., 2016), we chose the ecosystems in Silicon Valley, Munich, and Singapore, which are all successful ecosystems in a comparably large city in a developed economy but are still contrasts in terms of their geographical location, culture, and structure, as outlined above. To ensure comparability, our study centers around innovative and independent new ventures in predominantly technology related industries, in those developed countries, excluding entrepreneurial ventures that are based on economic necessities rather than perceived opportunities (Stephan \& Uhlaner, 2010) and subsidiaries of existing firms.

Our sample includes serial entrepreneurs, business angels, venture capitalists (VCs), and heads of accelerators and incubator programs with experience in the ecosystems in Silicon Valley, Munich, and/or Singapore. All our interviewees had an in-depth experience in new ventures, support novice entrepreneurs, and hold gatekeeper positions. We chose interview partners who are exceptionally successful players in the ecosystem(s) where they are active (see Table 1 and the Appendix 1 for more details). Due to their high level of performance, which is a result of years of experience and deliberate practice in those ecosystems, we consider them to be "experts" in the field. Table 1 provides detailed information about our interview partners including a short description of their positions and activities. Interviewees' age ranged from 26 to 65 years with an average of 47 years. With three female participants, the study reflects the maledominated nature of the field.

\subsection{Data collection}

The second author conducted interviews with 43 entrepreneurial experts, several of them interviewed twice, in English or German. Most interviews were conducted personally, at the informants' familiar setting; few were conducted via phone, due to scheduling restrictions. Travelling to all three ecosystems, the second author also got an impression of the environment at the respective locations. To capture the interviewees' perspective and minimize our influence on their responses, we used an interview protocol with open-ended questions (see Appendix 2) and allowed for flexibility to ensure that unexpected concepts can be introduced by interviewees (Glaser \& Strauss, 1968). Interviewees were asked to describe the ecosystems they are familiar with from their own personal perspective (Eisenhardt et al., 2016). They were also asked to explain what they think is specific about entrepreneurship in the ecosystems, how they think these specifics influence entrepreneurship, and their recommendations for the ecosystems. The interview duration varied from $40 \mathrm{~min}$ to $1.5 \mathrm{~h}$ with a total of $43.7 \mathrm{~h}$ of interview material.

\subsection{Data analysis}

Our data analysis followed an inductive approach (Eisenhardt et al., 2016) which allowed us to observe, consider, and integrate concepts and mechanisms that were not pre-defined but emerged from the data during the analysis process (Gioia et al., 2013). We iteratively went through three phases, which we describe in more detail in Appendix 3. First, in an initial round of coding, the second and fourth authors independently coded all interview data with the help 
Table 1 Sample information

\begin{tabular}{|c|c|c|c|c|c|c|c|c|}
\hline \multirow{2}{*}{$\begin{array}{l}\text { No } \\
(\#)\end{array}$} & \multirow[t]{2}{*}{ Short description } & \multicolumn{5}{|c|}{ Entrepreneurial Experience } & \multirow{2}{*}{$\begin{array}{l}\text { Age of } \\
\text { inter- } \\
\text { viewee }\end{array}$} & \multirow{2}{*}{$\begin{array}{l}\text { Length of } \\
\text { interview } \\
\text { (min) }\end{array}$} \\
\hline & & SG & GER & SV & Other & Years & & \\
\hline 1 & Start-up CEO/CMO, accelerator founder and business angel & $\bullet$ & & & & 18 & $45-54$ & 53 \\
\hline 2 & Serial entrepreneur with several rounds of funding & $\bullet$ & & & & 6 & $25-34$ & 39 \\
\hline 3 & $\begin{array}{l}\text { Innovator, start-up advisor and investor affiliated with a national } \\
\text { government investment arm }\end{array}$ & - & & & & 6 & $35-44$ & 57 \\
\hline 4 & Self-made serial entrepreneur & $\bullet$ & & & & 2 & $35-44$ & 44 \\
\hline 5 & $\begin{array}{l}\text { Entrepreneurship researcher, educator, author, mentor and business } \\
\text { angel }\end{array}$ & $\bullet$ & & & $\bullet$ & 20 & $55-64$ & 31 \\
\hline 6 & Serial entrepreneur and multiple start-up CEO/CMO & $\bullet$ & & & $\bullet$ & 18 & $55-64$ & 84 \\
\hline 7 & Entrepreneur, fund manager and investor & $\bullet$ & & & $\bullet$ & 15 & $45-54$ & 44 \\
\hline 8 & $\begin{array}{l}\text { VC, incubator co-founder, serial entrepreneur, start-up mentor and } \\
\text { entrepreneurship educator }\end{array}$ & $\bullet$ & & & $\bullet$ & 14 & $35-44$ & 52 \\
\hline 9 & Entrepreneur, business angel and entrepreneurship educator & $\bullet$ & & & $\bullet$ & 13 & $55-64$ & 40 \\
\hline 10 & Serial entrepreneur, social entrepreneur, advisor, business angel & $\bullet$ & & & $\bullet$ & 7 & $35-44$ & 38 \\
\hline 11 & Seed-stage VC, investor and $2 \times$ founder & $\bullet$ & & & $\bullet$ & 5 & $35-44$ & 41 \\
\hline 12 & $\begin{array}{l}\text { Serial entrepreneur and business angel with experience across } \\
\text { ecosystems }\end{array}$ & $\bullet$ & & $\bullet$ & & 19 & $35-44$ & 62 \\
\hline 13 & $\begin{array}{l}\text { VC, serial entrepreneur, founder of top-tier university incubator, } \\
\text { adjunct professor, author with several success stories incl. multiple } \\
\text { IPO's }\end{array}$ & $\bullet$ & & $\bullet$ & $\bullet$ & 30 & $55-64$ & 86 \\
\hline 14 & $\begin{array}{l}\text { Serial entrepreneur, managing partner of a large } \mathrm{VC} \text { fund and social } \\
\text { entrepreneur }\end{array}$ & $\bullet$ & & $\bullet$ & $\bullet$ & 20 & $55-64$ & 51 \\
\hline 15 & $\mathrm{VC}$ and managing director of an accelerator program & $\bullet$ & & $\bullet$ & $\bullet$ & 20 & $45-54$ & 53 \\
\hline 16 & Serial entrepreneur, start-up mentor and adjunct professor & $\bullet$ & & $\bullet$ & $\bullet$ & 16 & $55-64$ & 83 \\
\hline 17 & $\begin{array}{l}\text { Serial entrepreneur with investments from and experience across } \\
\text { multiple ecosystems }\end{array}$ & $\bullet$ & & $\bullet$ & $\bullet$ & 11 & $25-34$ & 79 \\
\hline 18 & $\begin{array}{l}\text { VC, start-up mentor, advisor and educator with an affiliation to } \\
\text { several international government funded accelerator and incubator } \\
\text { programs }\end{array}$ & & $\bullet$ & & $\bullet$ & 19 & $55-64$ & 63 \\
\hline 19 & $\begin{array}{l}\text { Serial entrepreneur, founder and director of a sales accelerator for } \\
\text { start-ups }\end{array}$ & & $\bullet$ & & $\bullet$ & 12 & $35-44$ & 53 \\
\hline 20 & $\begin{array}{l}\text { Serial entrepreneur and managing director of a top-tier university } \\
\text { accelerator program with experience across all three ecosystems }\end{array}$ & & $\bullet$ & $\bullet$ & $\bullet$ & 18 & $35-44$ & 57 \\
\hline 21 & $\begin{array}{l}\text { Serial entrepreneur, advisor and (co-)founder of several national and } \\
\text { international incubator and accelerator programs }\end{array}$ & & $\bullet$ & $\bullet$ & $\bullet$ & 33 & $45-54$ & 62 \\
\hline 22 & $\begin{array}{l}\text { Lead mentor of one of the biggest incubator programs, serial entre- } \\
\text { preneur and business angel }\end{array}$ & & $\bullet$ & $\bullet$ & $\bullet$ & 25 & $45-54$ & 93 \\
\hline
\end{tabular}


Table 1 (continued)

\begin{tabular}{|c|c|c|c|c|c|c|c|c|}
\hline \multirow{2}{*}{$\begin{array}{l}\text { No } \\
(\#)\end{array}$} & \multirow[t]{2}{*}{ Short description } & \multicolumn{5}{|c|}{ Entrepreneurial Experience } & \multirow{2}{*}{$\begin{array}{l}\text { Age of } \\
\text { inter- } \\
\text { viewee }\end{array}$} & \multirow{2}{*}{$\begin{array}{l}\text { Length of } \\
\text { interview } \\
(\min )\end{array}$} \\
\hline & & SG & GER & SV & Other & Years & & \\
\hline 23 & Corporate $\mathrm{VC}$, business angel and serial entrepreneur & & $\bullet$ & $\bullet$ & $\bullet$ & 15 & $35-44$ & 57 \\
\hline 24 & Serial entrepreneur and director of an accelerator program & & $\bullet$ & $\bullet$ & $\bullet$ & 11 & $45-54$ & 43 \\
\hline 25 & $\begin{array}{l}\text { Co-founder of leading gaming company, VC, start-up advisor and } \\
\text { business angel with affiliation to several International entrepreneur- } \\
\text { ship programs }\end{array}$ & & $\bullet$ & $\bullet$ & & 34 & $>64$ & 85 \\
\hline 26 & $\begin{array}{l}\text { Director of one of the biggest business angel networks, VC, entrepre- } \\
\text { neurship educator, serial entrepreneur and start-up mentor }\end{array}$ & & $\bullet$ & $\bullet$ & & 31 & $>64$ & 40 \\
\hline 27 & $\begin{array}{l}\text { Serial entrepreneur with affiliation to a government funded accelera- } \\
\text { tor program }\end{array}$ & & • & $\bullet$ & & 20 & $45-54$ & 84 \\
\hline 28 & $\begin{array}{l}\text { Serial entrepreneur and (co-)founder of a tech start-up with an inter- } \\
\text { national founding team }\end{array}$ & & • & • & & 15 & $25-34$ & 37 \\
\hline 29 & $\begin{array}{l}\text { Government funded VC, start-up advisor and } 1 \times \text { founder with a } \mathrm{PhD} \\
\text { in entrepreneurship }\end{array}$ & & • & • & & 14 & $35-44$ & 128 \\
\hline 30 & $\begin{array}{l}\text { Head of a government funded accelerator program, start-up advisor } \\
\text { and } 1 \times \text { founder }\end{array}$ & & • & $\bullet$ & & 3 & $25-34$ & 49 \\
\hline 31 & Serial entrepreneur and business angel & & $\bullet$ & & & 19 & $45-54$ & 75 \\
\hline 32 & Serial entrepreneur, founder and managing director of a VC firm & & $\bullet$ & & & 16 & $55-64$ & 98 \\
\hline 33 & $\begin{array}{l}\text { Serial entrepreneur, entrepreneurship educator and head of state- } \\
\text { funded entrepreneurship program }\end{array}$ & & $\bullet$ & & & 11 & $35-44$ & 68 \\
\hline 34 & $\begin{array}{l}\text { Serial entrepreneur, business angel and managing director at a VC } \\
\text { firm }\end{array}$ & & • & & & 8 & $45-54$ & 62 \\
\hline 35 & $\begin{array}{l}2 \times \text { founder and program manager at a university entrepreneurship } \\
\text { program and VC fund }\end{array}$ & & $\bullet$ & & & 8 & $25-34$ & 92 \\
\hline 36 & Serial entrepreneur with multiple successful exits & & & $\bullet$ & $\bullet$ & 30 & $55-64$ & 101 \\
\hline 37 & Serial entrepreneur with multiple rounds of VC funding & & & $\bullet$ & $\bullet$ & 15 & $35-44$ & 41 \\
\hline 38 & Serial entrepreneur with several VC funded start-ups & & & $\bullet$ & $\bullet$ & 7 & $45-54$ & 60 \\
\hline 39 & $\begin{array}{l}\text { Serial entrepreneur with several success stories incl. bringing a } \\
\text { venture from incubation to IPO }\end{array}$ & & & $\bullet$ & & 23 & $55-64$ & 79 \\
\hline 40 & Serial entrepreneur with multiple successful exits & & & $\bullet$ & & 18 & $55-64$ & 53 \\
\hline 41 & $\begin{array}{l}\text { Serial entrepreneur in the VR/AR industry turned VC and business } \\
\text { angel }\end{array}$ & & & $\bullet$ & & 9 & $35-44$ & 82 \\
\hline 42 & Social entrepreneur and $2 \times$ founder incl. one VC funded venture & & & $\bullet$ & & 6 & $25-34$ & 31 \\
\hline \multirow[t]{3}{*}{43} & $\begin{array}{l}\text { Start-up advisor and serial entrepreneur with several successful exits } \\
\text { incl. IPO }\end{array}$ & & & $\bullet$ & & 5 & $35-44$ & 55 \\
\hline & Average & & & & & 15.35 & 46.56 & 62.44 \\
\hline & Sum & 20 & 18 & 25 & 22 & & & 2685 \\
\hline
\end{tabular}

of MAXQDA to identify differences and commonalities in interviewees' statements (Gioia et al., 2013; Miles, Huberman, \& Saldaña, 2014). To increase validity, the first author then again coded the parts of the interview data which were identified as relevant. We compared and contrasted our observations and discussed our interpretations until we reached an agreement (Corbin \& Strauss, 2008). The third author was not involved in the data analysis but challenged our emerging findings from an external perspective (Strauss \& Corbin, 1994). In this process, we categorized statements about differences and specifics of the entrepreneurial ecosystems, and statements about what is perceived as typical as well as successful attitudes, decisions, and actions of entrepreneurs in an ecosystem (examples in Appendix 3). We found that interviewees reiterated narratives which indicate what is considered common, useful, appropriate, 
and/or successful in an ecosystem, and/or what is encouraged or discouraged; and those narratives were repeatedly suggested to drive tendencies towards specific approaches and logics of entrepreneurs.

Second, we iterated between the data and our interpretation as we discussed and explored different versions of data reduction and data display, which helped us drawing conclusions in a collaborative process (Miles et al., 2014). To structure our insights, we extracted repeatedly mentioned ecosystem constellations and grouped statements by whether they refer to the national culture, market characteristics, available resources, and networks. Moreover, we substantiated and labelled the identified narratives. Based on suggestions of the first author, we collectively challenged and adapted the labels until we agreed that they reflect the data, pinpoint the narratives, and are clear and understandable to outsiders. In the following and in all figures and tables, we use the final labels which we refer to with the letters (a) to (o). We concluded from our observations and interpretations that the narratives may constitute pathways via which ecosystems drive tendencies towards specific entrepreneurial approaches.

Third, to explore how narratives may shape tendencies in entrepreneurial approaches, we went back and forth between knowledge from previous research and the observations in our data (Miles et al., 2014). We could observe communalities in how mechanisms were described for each ecosystem indicating that there could be locale-specific influence mechanisms. When we investigated links between the narratives and concepts in previous literature, we came to realize that the concepts of effectuation and causation (Sarasvathy, 2001) can help us pinpoint the most striking differences between the ecosystems. Although we could not infer or empirically test causality with our research design, we could identify conceptual links between the narratives and tendencies towards either effectuation or causation. Based on a combination of arguments of our interviewees and arguments in the literature, we concluded that the ecosystem-specific mechanisms may create and reinforce tendencies towards either effectuation or causation. Therefore, we explored and visualized the links between the narratives and effectuation and causation (see Fig. 2). Our final analysis aimed at illuminating the whole mechanism, i.e., linking the differences between the three entrepreneurial ecosystems with the narratives about attitudes, decisions, and actions in each ecosystem, and showing which narratives may drive tendencies towards either effectuation or causation (see also Appendix 3).

\section{Findings}

We could identify commonalities but also differences across Silicon Valley, Munich, and/or Singapore. In the following, we describe what we identified as specifics in each ecosystem and how these specifics may spark narratives that create a tendency towards either effectuation or causation. Figure 1 provides an overview of all concepts, Fig. 2 shows the identified mechanisms, and Tables 2, 3, and 4 show illustrative quotes for each ecosystem. The letters in brackets in Fig. 1 and tables, and attached to arrows in Fig. 2, indicate the narratives identified in the interview analysis.

\subsection{Silicon Valley ecosystem and its relation to effectuation and causation}

The Silicon Valley ecosystem seems to facilitate effectuation and discourage causation (see illustration in Fig. 2 and example quotes in Table 2). Our interviewees repeatedly highlighted the stimulating entrepreneurial culture and the presence of extensive support for entrepreneurs. This environment was believed to encourage entrepreneurs to be confident and think big. The interviewees also emphasized the numerous possibilities for discussing and selling ideas, and for flexible experimenting. These possibilities were suggested to facilitate partnerships-oriented approaches. This focus on networking and flexibility fits well with the logics of effectuation. Another repeatedly emphasized characteristic, which is likely to contradict the predictive logics of causation, was the high speed of developments. Thus, although we discovered some causal logics-related to the competition in the market-we concluded that effectuation seems to be facilitated and causation primarily discouraged.

\subsubsection{Be confident, think big (a)}

When interviewees talked about the atmosphere, they described a strong entrepreneurial spirit and a 
Ecosystem Constellations

Ecosystem Specific Narratives

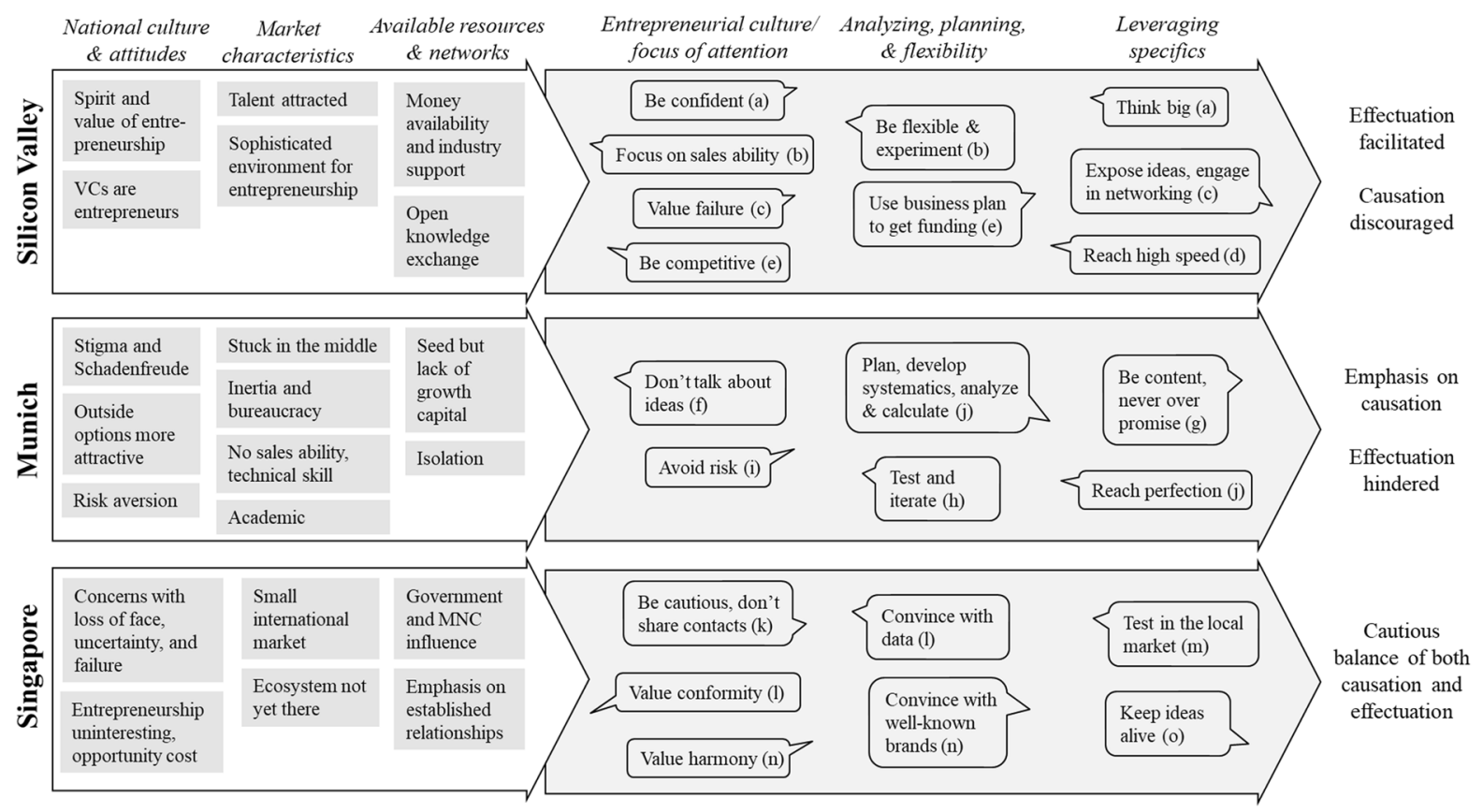

Fig. 1 Ecosystem constellations and ecosystem-specific attitudes, actions, and decisions. Letters in brackets categorize the narratives indicating which entrepreneurial attitudes, decisions,

high value of entrepreneurship. They reported that the entrepreneurial spirit could be felt all over the place, not only within incubators but even in most cafés. People seemed to be proud to be part of the entrepreneurial community, regardless of whether or not their business is financially successful. Interviewee 43 described that "In different cities, in different parts of the world, if you start a company and it fails, I think you lose a little bit of the family name or you lose the ability to find stability later. And I think here if you fail, it is almost like an embrace. Everybody wants to have coffee with you to care about what you learned. You know, what was the experience like and how did you experiment? And wow that is so amazing. And when are you going to start your next company?" Our interviewees highlighted that in this community, entrepreneurs can benefit from social and financial support and a sophisticated and mature environment with many different stakeholders including serial entrepreneurs and industry partners.

A strong entrepreneurial spirit was believed to inspire high confidence, even described as and actions were considered common, appropriate, or successful in an ecosystem by our interview partners. Tables 2, 3, and 4 show illustrative quotes

overconfidence, in entrepreneurs. This spirit was believed to encourage thinking big. VCs looked out for and encouraged entrepreneurs who were inclined to an idea and were able to convincingly sell the potential in that idea. Describing this tendency, Interviewee 25 highlighted that "In the US people think big. I mean it takes as much work to build a hundredmillion-dollar company as it does to build a billiondollar company." Appearing confident and thinking big allowed entrepreneurs to reach out for early precommitments of stakeholders who could help grow a project, and confidently sell an idea even if the idea is not yet concrete. Therefore, entrepreneurs were considered to be able to reach out to many potential ends and leverage contingencies along the way such that these processes $(a+$ in Fig. 2$)$ facilitate effectuation.

\subsubsection{Be flexible and experiment, focus on sales ability (b)}

Entrepreneurs were believed to be pushed to constantly refine their ideas. The advice of VCs to leverage the availability of money and support and the 
constant open exchange in the community encouraged entrepreneurs to continuously work on their product and its marketability. The advice of the VCs in Silicon Valley, who often have entrepreneurship experience themselves, was believed to support entrepreneurs in being flexible and experimenting with ideas. Entrepreneurs were encouraged to learn by constantly talking about and selling their ideas and that way to leverage contingencies. Our interviewees highlighted that VCs in Silicon Valley relied their investment decisions and advice on their evaluation of entrepreneurs' sales ability and passion, more than their product expertise. Entrepreneurs seemed to learn to sell their ideas along the way. The belief in the value of flexible experimenting, and the support and possibilities for this approach, suggested a predominance of effectuation (b+in Fig. 2).

\subsubsection{Expose ideas, engage in networking, value failure (c)}

The exchange in networks was considered to be an opportunity for entrepreneurs to expose their ideas for products and services, and their general approaches (e.g., to marketing), despite risks of being copied. Our interviewees emphasized that all entrepreneurs were expected to openly discuss their ideas because this allowed them to leverage the advice and support that is offered in the community. They described that entrepreneurs talk a lot about money, which was believed to be less common in Munich and Singapore. Moreover, it was repeatedly highlighted that the spirit in Silicon Valley carried along with the value of failure. Failure was seen as a highly valuable learning experience, by some even as a necessary experience for becoming an expert entrepreneur. Open exchange of knowledge and talking to potential partners even about money and failure was considered a specific characteristic for Silicon Valley. The exchange was also described as extraordinarily valuable in Silicon Valley because supporting VCs were considered to have a lot of experience, a good network, and motivation to "give back." Furthermore, the connection with industry partners and academia was perceived as closer than in Munich and Singapore. For these reasons, entrepreneurs were expected to focus on networking and building partnerships, which again suggested tendencies towards effectuation (c+in Fig. 2).

\subsubsection{Reach high speed (d)}

The entrepreneurial spirit and the support by experienced VCs were seen as reason why entrepreneurs can reach high speed of development in Silicon Valley. Entrepreneurs were considered to profit from business models that allow for fast and scalable growth because realizing growth potential was perceived to be easier in the US domestic market, compared to the German and Singaporean markets, due to its size which was considered large enough to scale almost any business model. Entrepreneurs were recommended to let go if the growth potential could not be quickly realized, they were advised to go for "all-or-nothing." The clarity of the processes of how entrepreneurs get funded and the experience of VCs, who usually had gone through many funding processes themselves, were believed to allow for high speeds of development. Silicon Valley was therefore believed to value speed over quality. Entrepreneurs coming from other locations were described to be regularly surprised by the enormous pace. To keep up with the speed, entrepreneurs were encouraged to talk about their idea with VCs very early and go to market as early as possible. Due to the high development speed and the necessity of fast reactions, accurate prediction and causal planning were seen as detrimental, such that causation was discouraged (d-in Fig. 2).

\subsubsection{Be competitive, use business plan to get funding (e)}

The Silicon Valley region was believed to attract "the best talent," particularly people educated in tech and IT, and people keen on entrepreneurship and therefore ready to take risk. On the one hand, the availability of talent was considered to stimulate a highly valuable discussion in the network, suggesting a focus on exchange with partners, relating to effectuation $(c+$ in Fig. 2). On the other hand, the availability of talent was considered to drive competition for talent, suggesting a need for competitive analysis which relates to causation (e+in Fig. 2).

Entrepreneurs were also believed to require some kind of business plan and a competitor analysis, focused on the closest successful competitors, in the process of securing funding. Such planning and analyses suggested that entrepreneurs were, despite the otherwise rather effectuation-oriented processes, 

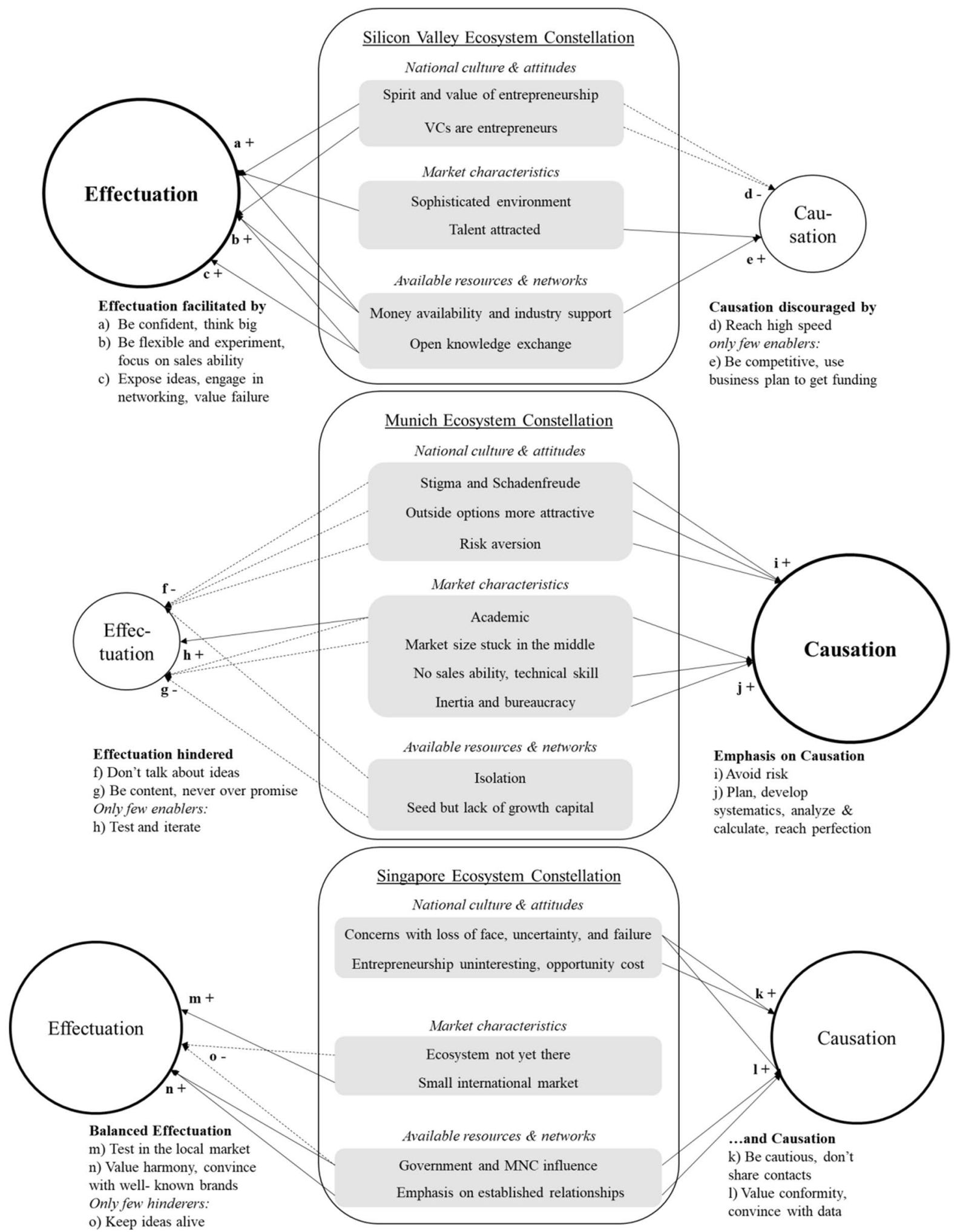
4Fig. 2 Ecosystem constellations and effectuation and causation. The size of the circles for effectuation and causation indicates their relative prominence in the ecosystem. Letters attached to arrows categorize the narratives indicating which entrepreneurial attitudes, decisions, and actions were considered common, appropriate, or successful in an ecosystem by our interview partners. Tables 2, 3, and 4 show illustrative quotes

pushed to causal thinking in the process of getting funding ( + in Fig. 2). Nevertheless, such plans were described as often non-formalized in Silicon Valley - one respondent even said that they could be "on a napkin" (Interviewee 24).

\subsection{Munich ecosystem and its relation to effectuation and causation}

The Munich ecosystem seems to emphasize causation and hinder effectuation (see illustration in Fig. 2 and example quotes in Table 3). Due to perceptions of negative attitudes in the entrepreneurial culture and the isolation of entrepreneurs, entrepreneurs were believed to avoid risk and to be reluctant to talk about their ideas. Moreover, the market structure and the availability of resources only for seed funding were believed to make entrepreneurs content with very little scaling. Also, due to the academic-perfectionist focus of many VCs, supporters, and potential partners, entrepreneurs were warned to never over promise. Entrepreneurs were described to have a focus on planning, systematics, analyses, and calculations and a tendency towards perfectionism, which suggested a focus on causation. Only the tendency towards testing and iteration, stemming from the academic background of many entrepreneurs, suggested effectuation.

\subsubsection{Do not talk about ideas (f)}

Attitudes in Munich were described to be characterized by the Germans' uncertainty avoidance and low value of and respect for entrepreneurship. Entrepreneurs were believed to be afraid of failing and outsiders doubt whether starting a business was worth the effort. The doubt whether it is worth the required effort and risk even were believed to create Schadenfreude for failed entrepreneurs because failure proved that the attempt had indeed not been worth it. Interviewees also described that, after failure, entrepreneurs were stigmatized in the community and entrepreneurs then had difficulties to get funding again. Due to the negativity around entrepreneurship, entrepreneurs were considered to be unlikely to talk about their ideas very often. Interviewee 30, for example, said that "Germans are always like 'hm, well, I better don't tell you too much. Wow, maybe you steal my idea." Being afraid that other people might steal ideas was a concern that was particularly present in Munich. Those mechanisms were suggested to make entrepreneurs careful in conversations with outsiders because entrepreneurs worry others could steal their idea or find the business idea-or the idea to start a business-ridiculous. Networking was in general perceived to be less extensive than in Silicon Valley. The entrepreneurship community was described to be rather isolated from more established companies which was considered a reason for the lack of networking and the lack of interest from industry partners to invest in start-ups. Due to the difficulties to get in contact with local large firms, entrepreneurs were encouraged to get funding from overseas. Thus, the ecosystem in Munich seemed to hinder the partnerships-oriented effectuation approach (f - in Fig. 2).

\subsubsection{Be content, never over-promise ( $g$ )}

Our interviewees saw a lot of options for getting seed funding from the government in Munich. Initial funding was perceived to be easier than in the competitive environment in Silicon Valley, but they saw hardly any options for getting funding for growth and scaling. Additionally, due to the academic-perfectionist focus of many VCs, supporters, and potential partners, entrepreneurs were warned to never over promise. Moreover, the size of the German domestic market, which was considered the starting point for most start-ups in Munich, was labelled as "stuck-inthe-middle," neither large enough to scale nor small enough for low-scale experimentation. The difficulties of growth and scaling were considered to be a reason for entrepreneurs being content without largescale developments, and therefore also without reaching out for many pre-commitments, as suggested by effectuation ( $g-$ in Fig. 2). 
Table 2 Sample quotes for the ecosystem influence in Silicon Valley

Silicon Valley

Ecosystem constellation

Ecosystem-specific attitudes, decisions, and actions

\section{Spirit and value of entrepreneurship}

So culture wise, you see, there are so many entrepreneurs and there are so many opportunities and there is this entrepreneurial spirit that it's very easy to find other entrepreneurs [...] so people respect you and they value you and then the society in general, really really admires and respects entrepreneurs, they consider them almost like national heroes, almost. Interviewee 37

They are talking about start-ups all the time. And that does not happen in Munich. You go in a restaurant and in any restaurant, there is at least a few of them that are talking about start-up stuff in the Bay area, everywhere in the Bay area, not true in Munich. Interviewee 25

\section{VCs are entrepreneurs}

But one of the major differences from the US market to the German market is not just the availability but also the distribution of venture capital. And who makes decisions there / Many venture capitalists in the USA, here in the Valley, have founded a business themselves. Interviewee 30

They just have this whole spirit, they know what it means to have or to be a start-up they know how to act, how to do partnerships or what is important for the start-ups and at the same time, they know what is important for themselves as a big company and thus it often works even better than in Germany or in Singapore where somehow you have managers who have no idea whatsoever about start-ups. Interviewee 27

\section{Talent attracted}

You have a lot of people who are doing very interesting things, so there's an energy around start-ups. Obviously, the other piece of it is - that attracts the top talent. This is the destination for technologists. It's where everything's happening. It's the mothership. As a result, you find the quality of talent here is immense. Interviewee 43

And when it comes to talent, the pool here is very, very extensive. Interviewee 28

The Valley is like this center of technology because you have everybody who can help you build a business is sitting there. [...] Institutional knowledge there is very high. Interviewee 12

\section{Sophisticated environment}

Silicon Valley offers the ecosystem well. Legal systems, financial systems, accounting, banking systems, bank to banks, service providers will handle all this very efficiently for you. Interviewee 26

Silicon Valley is a very mature start-up community. Interviewee 14

I'd say basically investors here are more experienced and there is a better structure, it is clear how a deal looks like, you do not have to renegotiate every deal but either you are in or you are not in. Interviewee 27

\section{Monev availability and industry support}

There is always money available, it is a question of how much and at what point. Interviewee 14

It is a bit different, especially in the US where you can raise a lot of money and, in some cases, build competition between investors. It is more of a seller's market there. Interviewee 29

In the Silicon Valley you can be a lot more informal. And a lot of times you hear about entrepreneurs that never even expected to raise money but then investors came to them and they ended up raising money. Interviewee 28

\section{Open knowledge exchange}

Everyone has always $20 \mathrm{~min}$ for you and everyone is always open. Interviewee 30

The difference is that you, it is much easier to make strategic alliances in the

United States than it is to make them in Germany. Interviewee 21

Here people are not hesitant to say 'I know somebody. Let me give you their name and I'll give that person your name and then you two try to meet.' Interviewee 25

\section{Be confident, think big (a)}

They have this confidence, that they can go out and do it. And even if they get a bunch of "No I don't want to talk to you," they still keep going. Interviewee 25

People, Americans, you know this is not always the case but Americans tend to believe that they are the best at whatever they do. Interviewee 25

American entrepreneurs are more willing to lose everything -whatever that means- than the Germans are. Interviewee 21

\section{Be flexible and experiment, focus on sales ability (b)}

Yeah, I think the American companies are much more open to changing faster than the German companies, they are not as stuck on their ideas I would say that there is a lot more flexibility. In the US people think big. I mean it takes as much work to build a hundred-million-dollar company as it does to build a billion-dollar company. Interviewee 21

Here in the US market, people are crazier-in a good way-about testing new things, discovering new things, playing with new things. Interviewee 30

\section{Expose ideas, engage in networking, value failure (c)}

Here, people are encouraged to talk about their idea all the time. Who cares if somebody else comes up with a copy of it or a better version of it? The answer here is, well if somebody else can listen to your idea, figure out a better way to do it and do it faster than you can, well shame on you. Interviewee 25

You don't find that openness and willingness to share ideas and perspectives in many parts of the world. Interviewee 30

So in Silicon Valley failure is a good thing, right, in a convoluted way.

So if two people come to me for funding in Silicon Valley, one guy has had no failure and one has had a failure. The guy who has had a failure is more likely to get funded which is backwards what people think in Asia. Interviewee 14

Someone who is a leader of a company who has never failed, that is a red flag to them. It is a caution note them. They feel like if you've been successful great, but you are not seasoned enough if you haven't had failure. Because the failure teaches you as much as success does and sometimes even more. Interviewee 25

\section{Reach high speed (d)}

Silicon Valley is just like, everything is a lot faster, right, here. Interviewee 28

It's all about agility and instead of just pouring a lot of resources and time and effort and money and then walling it out, today you can do certain steps, be lean, you know, and then test it as you go. Interviewee 37

Americans also like to launch intermediate versions, their beta versions.

Where the product is finished but certainly not perfect. Interviewee 30

\section{Be competitive (e)}

He needs to have that kind of competitiveness between even the founders

because they will make mistakes and they need to challenge each other. Interviewee 40

The start-ups that come over from Europe, there is two more things that they miss: They miss, they underestimate the competition completely. And they underestimate the pace of engineering and marketing development here. [...] It is like that horse race. In the minute you get here, driiiiing, they are off and running and there is someone still at the front. You are in this horse race. And the second thing you learn is, if you are not in the first three horses, it is over. And it doesn't matter if you are tired, it doesn't matter if you are in the front all the way around the track and you need to slow down to catch your bro, it just doesn't matter. Because if you don't keep running, full speed, they are going to chase you down and take your business. Interviewee 22

\subsubsection{Test and iterate ( $h$ )}

The entrepreneurial ecosystem was described as academic because a high percentage of entrepreneurs developed their idea by creating a business model around a result of a scientific study. Entrepreneurship centers of the universities are considered the main actors helping these entrepreneurs to build new 
Table 3 Sample quotes for the ecosystem influence in Munich

Munich

Ecosystem constellation

\section{Stigma and Schadenfreude}

There is generally a bigger stigma held against you for failing. Interviewee 21

If you fail and damage your reputation in Germany, you are doomed forever. Interviewee 30

If someone is really successful, then you are not really pleased for them either. Interviewee 35

There is a negative feeling about new ideas. Interviewee 22

You are either the stupid founder or the successful entrepreneur, who then faces jealousy. Interviewee 33

\section{Outside options more attractive}

There is lots of options today to get more money at a real company if I can use that word or an established company than when you are going to get your start-up. Interviewee 26

The consequence of such a failure in Germany is often rather that one says well then I'll return to the corporate world and try to make money and not 'then I'll just do it again.' [...] The risk is actually more present in opportunity costs. Interviewee 23

\section{Risk aversion}

You always have a certain resistance to innovation in Germany. Interviewee 30 Germans are a lot more risk-averse than Americans. Especially as a young founder, like I just mentioned, this is connected to the high monetary reserves that you must form. Interviewee 30

Stuck in the middle

I'd say "stuck in the middle" [...] too big to neglect and too small to really think globally. Interviewee 27

Most of them initially only have the German market in their business plan. Interviewee 33

What we are just somehow missing, and that is of course a real problem, we do not have this single market [in Europe]. You have to start pretty quickly to do something in different languages. Interviewee 35

\section{Inertia and bureaucracy}

In Germany you are very stuck in the old system, you make a call, the secretary answers, she tells you they will get back to you in 6 weeks and then they get back to you in 6 months or not at all. Interviewee 21

Apart from that, generally, bureaucracy is always listed as a constraint. Interviewee 31

In Germany you have to have 25,000 euros in reserve in order to even start a $\mathrm{GmbH}$. A lot of lawyer involvement, many lawyers, etc. Interviewee 30

\section{Academic, no sales ability, technical skill}

Here people often act naively and without sales know-how. This is a big problem that we have in Germany and it sustainably inhibits the success of our start-up scene. Interviewee 34

A scientist has somehow developed a technology, e.g., to detect any pollutants in the water. This development was made for a completely different topic as part of a research project and now it's about, ok, we now have this technological development how could the product, service or business model behind it look like, to start a business behind it. A typical task that we often have. Interviewee 35

\section{Seed but lack of growth capital}

I think that the downside in Germany is that, I do think it is true that there is a hole in the financing market after Seed. I think that it is in-between Seed and early stage there is just simply a hole and it is hard to get money, there is too many deals chasing too little money. Interviewee 21

There surely is a relatively large basis for seed and very early stage, but it is significantly more difficult to do a second, third round afterwards. Interviewee 32

\section{Isolation}

I think you have less openness from large corporations in Germany to work with start-ups. Interviewee 21

I think the problem is not in the German start-ups but more in the German industry and their engagement in young firms and innovative ideas. Interviewee 31

Cooperation in which constellation whatsoever with established companies is, I guess, significantly easier in the USA than it is in this country here [Germany]. Interviewee 33
Ecosystem-specific attitudes, decisions, and actions

\section{Do not talk about ideas (f)}

Lots of times people outside the U.S., Germany too, they don't want to talk about start-ups. They don't even want to talk about their idea if they have a start-up idea, a little group that is working on something. They won't talk about it. Because they are afraid somebody is going to steel it. Interviewee 25

I think, no, I know, that the exchange between start-ups here [in Silicon Valley] is much more open and honest than in Germany. More open means that you do not have a problem to talk about numbers here. [...] much more information is exchanged than in Germany. Interviewee 27

One would rather have a guess in one's quiet room, about what would have to be done, instead of actually speaking to somebody in person. Interviewee 23

\section{Be content, never over-promise ( $g$ )}

A German company would never overpromise, would just not happen. Interviewee 19

So what certainly is essentially a bit difficult for Germans is just thinking big. Interviewee 33

But in Europe, they tend to be satisfied with a hundred-million-dollar company. Interviewee 25

\section{Avoid risk (i)}

Culturally, the people are also a bit more risk-averse and then maybe just do not max out five credit cards to pay for whatever things for their start-up or do not, how to say, take up a mortgage on their house to make a start-up. That's probably not the case in Germany, that's what you do here [in Silicon Valley]. Interviewee 29

In Germany you do it in a slightly more half-assed way a little bit on the security aspect. This minimizes the loss. But the potential is not exhausted either. Interviewee 27

\section{Plan, develop systematics, analyze, \& calculate, reach perfection (i)}

European style is to do all this planning. Plan, plan, plan. If they want to get money they have to submit all this very well thought through business plan. Interviewee 22

When a German company, one of the experiences we had, they want the contract and then in the contract everything needs to be specified what will be done on what day when. Interviewee 19

I can definitely say that the Germans are very good at it, take it very seriously and really do their work and when we ask them to come up with a market analysis, the ones I'm thinking of right now, they have delivered very comprehensive reports of who is out there, market research. Interviewee 24

Germans work until the product is perfect. Due to the fact that there is no external feedback, they are very much at risk of developing the product in a way that fails to address customer needs. Interviewee 30

That's what I think is typically German, perfectionism, over-engineering and until the German team dares to sell a product, the comparable American competitor has already realized quite some sales with semi-finished products. Interviewee 33

I think Americans live from marketing. I had addressed it indirectly. For the Americans it is more important to generate sales than to build the perfect product. And in Germany I sometimes have the feeling that it is exactly the other way around. Interviewee 27

I think in comparison to the USA, the big difference here is I think that we at least try to do it more systematically in the beginning, which means we analyze more and try to get data and information whereas I think Americans just run for it, they start doing faster and learn in the market. Interviewee 35 
Table 4 Sample quotes for the ecosystem influence in Singapore

Singapore

Ecosystem constellation

\section{Concerns with loss of face, uncertainty, and failure}

The fear of loss of face actually doesn't help people take a risk. Interviewee 3

And then what major difference is risk-taking ability of the entrepreneur and

the risk taking of all the surrounding [...] In Asia they see ah that guy had a hit, let's fund him and this guy, he had a failure, he lost money for his investors. And people are careful with investing there, which is backwards how it is [in Silicon Valley] [...] It is taboo, failure is a taboo. Interviewee 14

If you declare bankruptcy, it's so difficult to get out of, you are not allowed to travel, etc. Interviewee 1

\section{Entrepreneurship uninteresting, opportunity cost}

Singapore has a culture of corporations. If it comes from a big corporation, it's good. If it comes from a small company, I'm not interested. Interviewee 12

People get paid very, very well to work for the government because the government has always recognized the importance of human resource. [...] So if you even remotely look like you are one of the best and the brightest, the system has already sucked you in before you have a chance of thinking of being an entrepreneur. Interviewee 7

\section{Small international market}

So technical skills are very difficult to find, so you try to find local skills and then you can't and then you go outside and find someone and try to bring them here. Interviewee 14

Singapore is so geographically central to the world. [...] Singapore is a wonderful hub for expertise as much as anything, there are a lot of smart people—right? Lots of money, lots of smart people but very little depth. Interviewee 17

So Singapore is just a place where you can/you have access to resources, to financiers and maybe, to some talent. But very quickly you will outgrow Singapore. Interviewee 12

\section{Ecosystem not yet there}

Singapore, we are probably just at the point where there are some financiers. We don't have that many successful companies who have done it, who have kind of created huge value. Interviewee 12

And then, if you look at in Singapore or in Asia generally, there is still a very poorly developed VC scene, especially in the idea stage. Interviewee 7

It's also because we don't have that generational experience, serial entrepreneurs mentoring the new entrepreneurs, $[\ldots]$ In fact we have so few of those that we had to almost import them, really invite them to come to Singapore. Interviewee 3

\section{Government and MNC influence}

Oh yeah, everything is coming from the government. This is Singapore. Without the government nothing happens. Interviewee 5

Very strong control and essentially central planning. Interviewee 16

They have a lot of funding schemes right or investment schemes like they will co-invest, they give you bonds, you know various type of funding available. And they can tweak that, so they might say one day for this particular scheme it used to be this, this, this now we only want this or vice versa. Interviewee 1

\section{Emphasis on established relationships}

I think people here do, in Asia, the Asian business, they do a lot on networks that they have built of a long period of time. Interviewee 19

They make very strong ties in primary school and secondary school, not so much when they are older. Interviewee 5

Most of Asia that we sell to it's by trust and if you have done business with them before or you know start business on a smaller scale and you gain trust and then grow the, you know, contracts. With US it is more you pitch and if they like the product then they go with you. Interviewee 38
Ecosystem-specific attitudes, decisions, and actions

\section{Be cautious; do not share contacts ( $k$ )}

They don't get out of their you know they stay in the comfort zone. Interviewee 16

Whereas here, people will hesitate a bit in the beginning. Because I don't want to send you, as a start-up, to a large organization with untested product, right? Because my credibility is on the line. [...] So people are a bit more reserved. Interviewee 14

So I don't share my network here, I am very careful with my network for the reasons like anything else like my reputation, the respect and the seriousness you bring to it, is the value you are essentially contributing. Interviewee 15

\section{Value conformity, convince with data (l)}

In Singapore, the stereotype is here people get through the structured, homogenous education process through primary, secondary school and university, where, and this is the stereotype, where compliance, acceptance, conformity are the prized characteristics. Interviewee 9

If somebody tall like you with a little bit more grey hair says "hey, do it like this, and hey, go here." [...] They just take the plane and go. Interviewee 14

It's underestimated how important data is from day one, instead of after a while. You need to start collecting data from day one and test it against your assumptions. Interviewee 6

But here VC's here are little bit more conservative and think "Hey wait a minute, show me a little more and OK now you show me a little more" and as you grow the numbers, I will give you some more money. Interviewee 14

\section{Test in the local market (m)}

And Singapore actually offers quite a safe, I suppose, we call it control tower for your operations in the rest of Asia. At least here, there's rule of law, there'squite transparent in the way we do business. Interviewee 3

In the past two generations it has become quite wealthy, it has excellent infrastructure, a strong consumer market, etc. Interviewee 15

\section{Value harmony, convince with well-known brands (n)}

I think in Eastern cultures there is often this overriding desire often for harmony, of the group, over the experience of the individual. Interviewee 15

So one of the very popular thing to do in Asia is to have one page full of logos. $[\ldots]$ every advert, every person, everyone. Which means you see, we see thing. Hey, hey we'll work together and then they put a logo. So there is this logo thing. Interviewee 14

\section{Keep ideas alive (o)}

Now the problem there is that big ideas, that should die a natural death with the harsh reality in the market, you try to take this product or service to market and it should die because nobody wants it. The problem is all these sources of funding give you runway to keep these things going. And so what I do see is things that should die the death, stagger on, [...] trapped in ideas that will kind of become zombies. Interviewee 9

I think in Singapore, the stakes are just lower in general. [...] Sure they don't earn a salary but if they lose, they don't lose that much actually really. And there is not much reputation at stake. Interviewee 23

I don't know how much government involvement is good. So I think it restricts when you take out all the risks it seems then it doesn't work either. Interviewee 16 ventures. Due to the academic background, entrepreneurs were considered to have a tendency towards testing and iteration, an approach that fits effectuation $(\mathrm{h}+$ in Fig. 2). Testing and iteration, however, were not specific for Munich but described for all three ecosystems. 


\subsubsection{Avoid risk(i)}

Entrepreneurs in Munich seemed to consider entrepreneurship a risky option. The abundant compelling job offerings by large companies, the attractive alternative career options, and high opportunity costs for potential entrepreneurs were expected to contribute to this attitude. Germans who choose an entrepreneurial career, which was here considered an unpopular choice, were described to avoid risk wherever possible. In line with this notion, Interviewee 20 highlighted that start-ups "try to minimize failure across the board" that they "indoctrinate people that you shouldn't fail" and that, if they failed, they "cannot be part of the system" anymore. Also, the stigma and Schadenfreude, as described above, are believed to make entrepreneurs cautious. Furthermore, the general tone when interviewees described their ecosystem was a lot more negative and pessimistic for Munich than for the other ecosystems. The negativity and focus on risk avoidance suggested a tendency towards causation ( $i+$ in Fig. 2) which aims at avoiding risks and contingencies.

\subsubsection{Plan, develop systematics, analyze, and calculate, reach perfection $(j)$}

The academic background of entrepreneurs was also considered a reason for entrepreneurs' very structured approaches that build on analyses, calculations, systematics and planning. Interviewee 25 highlighted that "German companies are much more likely to have very detailed plans, which is good as long as they have some flexibility." VCs in Munich were believed to focus on evaluating technical expertise, instead of sales ability. Entrepreneurs were described to perfection their products and services for a long time. Our interviewees described, in a rather sarcastic way, that entrepreneurs end up testing and iterating towards perfection and at the same time never talk about their ideas with outsiders and thus postpone going to market again and again. Entrepreneurs refraining from overpromising were believed to slow down getting funding and first customers. Munich was believed to value perfection over speed. The ecosystem was also described by high levels of inertia and bureaucracy with detailed contracts, usually examined by lawyers. Due to the focus on details, introducing radical ideas was considered to be complicated. Entrepreneurs were encouraged to provide detailed analyses and plans that convince lawyers and VCs; details were considered a necessity for any kind of collaboration. The need for detailed analyses, calculations, and predictions again suggested focusing on causation $(j+i n$ Fig. 2).

\subsection{Singapore ecosystem and its relation to effectuation and causation}

The Singapore ecosystem seems to establish a cautious balance between effectuation and causation (see illustration in Fig. 2 and example quotes in Table 4). Entrepreneurs were described to be cautious due to tendencies of being concerned with loss of face, and afraid of uncertainty and failure. The market was considered to be good for testing and iteration but, due to adverse incentives, the ecosystem was believed to not yet unfold its full potential. Resource allocation was believed to be strongly influenced by the government and MNCs, and they were perceived to require data early on. Networks were described as very important, particularly established relationships, such that entrepreneurs were encouraged to cultivate relationships by adhering to values of harmony and conformity. Some recommendations suggested causation, i.e., data-driven analyses, planning to avoid risk, conforming to established procedures, and others effectuation, i.e., building partnerships and experimentation.

\subsubsection{Be cautious; do not share contacts $(k)$}

Attitudes in Singapore were characterized by high levels of uncertainty avoidance. In addition, loss of face was considered to be a salient concern, originating in the national culture. Like in Munich, entrepreneurs who failed were expected to get stigmatized and have difficulties to get funding for future entrepreneurial attempts. Interviewee 14 described that "In Asia they see ah that guy had a hit, let's fund him and this guy, he had a failure, he lost money for his investors. And people are careful with investing there, which is backwards how it is [in Silicon Valley] [...] It is taboo, failure is a taboo." In a similar vein, Interviewee 14 emphasized a low "risk-taking ability of the entrepreneur," low "risk taking of all the surrounding" and that with "ability to stay strong and be the decision maker CEO, there aren't too many of those here." Although wealthy potential 
investors were believed to be present, those were also believed to be reluctant to invest in entrepreneurship. Singapore was perceived to be oriented towards corporates, not start-ups. The attractiveness of working for MNCs or the government was considered a reason why entrepreneurship was seen as uninteresting and among the last career options. Interviewee 7 even said that "You go and be an entrepreneur because there was nothing better for you to do." The general hesitation regarding entrepreneurship and the concerns with loss of face and failure were suggested as reasons for entrepreneurs being particularly cautious. Entrepreneurs were also perceived to be reluctant to openly share their contacts, due to the high value of relationships. The low value of entrepreneurship, the cautious attitude towards entrepreneurship, and the reluctance to share contacts suggested a tendency towards causation ( $\mathrm{k}+$ in Fig. 2) because causation focuses on prediction to avoid risks.

\subsubsection{Value conformity, convince with data (l)}

The Singaporean culture and a focus on building and maintaining long-term relationships were considered reasons why entrepreneurs focused on conformity. Established relationships were perceived to be of high value such that entrepreneurs were encouraged to focus on relationships that they already had for discussing ideas and getting first customers. Specific for Singapore also was the emphasis on the strong influence of MNCs and the government. MNCs were perceived to be difficult to convince to invest in entrepreneurship. The government's extensive support for initial funding was perceived to orient entrepreneurs' attention towards specific fields that the government considered to be important. Entrepreneurs were encouraged to conform with requirements and to use data to proof the fit of their idea with the government's or MNCs' strategies. Conformity also suggested adhering to rules. Adhering to rules and the necessity of analyses and predictions fit the linear and predictive logic of causation (1+in Fig. 2).

\subsubsection{Test in the local market ( $m$ )}

The market was perceived to be small and characterized by a high level of internationality. Interviewee 3 said "You can't just succeed in Singapore and expect to be big. Singapore is small. So you need to think multi-country." Labor supply is perceived to be limited and recruiting overseas to be common. The small size and high percentage of foreigners was believed to make entrepreneurs think about internationalization and thus to consider growth and scaling early on. Although teams containing many nationalities were perceived to be common in all three ecosystems, the orientation towards internationalizing was considered a necessity only in Singapore. Scaling was considered to be particularly difficult because scaling would require translations to other languages and adaptations to very different requirements in other countries. Nevertheless, the local market was perceived to provide a good test environment before scaling on the global market. Interviewee 9, for example, said that "You can launch products, you can pilot things here, prototype things here. It's quite a controllable environment to do that in. It's a safe environment." As it was considered to be easy to take things back when they don't work, entrepreneurs were encouraged to quickly test and iterate in the local market. Although this testing and iterating was not specific for Singapore, the market was considered ideal for experimentation with scaling for the international market in mind. Such experimentation fits effectuation because experimentation is part of the effectuation logic (o+in Fig. 2).

\subsubsection{Value harmony, convince with well-known brands ( $n$ )}

The aim to maintain long-term relationships was believed to make entrepreneurs focus on harmony. VCs were believed to focus on relationships such that they blindly trust their personal network. This focus on relationships appeared logical because network connections were considered to be important to reach legitimacy in conversations with the government and MNCs. Entrepreneurs were encouraged to convince VCs not only with data but also with logos of partners, which appeared to be a specific habit in Singapore. The focus on networks and well-known brands, combined with the focus on harmony, was considered to help in building partnerships, trust, and precommitments, and thus suggested effectuation $(\mathrm{p}+$ in Fig. 2). 


\subsubsection{Keep ideas alive (o)}

Our interviewees felt that the ecosystem did not yet unfold its full potential. Getting funding from the government was perceived to be comparatively easy which was considered a reason for the too low levels of commitment among entrepreneurs who received funding. Interviewee 20 also observed that "The problem is all these sources of funding give you runway to keep these things going. And so what I do see is things that should die the death, stagger on." The funding was believed to keep new ventures alive even when business models did not prove to work in the market. In this situation, radical adaptations along the way were perceived to be hindered because entrepreneurs stick to the approach that they had outlined to get funding. Selection and survival mechanisms were therefore perceived to be out of order. Discouraging entrepreneurs to constantly adapt and actively test new ideas contradicts the principles of effectuation ( $\mathrm{n}-$ in Fig. 2) which would suggest leveraging contingencies along the way.

\subsection{Contrasting the ecosystems}

We could identify specific factor constellations in the ecosystems in Silicon Valley, Munich, and Singapore, and could observe communalities in how mechanisms and links between factor constellations, narratives, and entrepreneurial approaches were described for each ecosystem. Based on these observations, we suggest there may be locale-specific influence mechanisms via narratives driving tendencies towards effectuation or causation.

Effectuation seemed to be facilitated by the narratives in Silicon Valley but hindered by most of the narratives in Munich; in Singapore, some narratives seemed to help others to hinder effectuation (see arrows on the left side in Fig. 2). One central aspect of effectuation is building partnerships. Our findings indicate that, in Silicon Valley, encouragement of open and intensive exchange about ideas facilitates partnerships-oriented approaches whereas a cautious and reserved communication attitude in Munich hinders partnership building. In Singapore, networks and partnership building were described as relevant but entrepreneurs to be encouraged to be cautious in conversations and to rely on established relationships. Thus, building partnerships seemed to be encouraged in Silicon Valley, and also facilitated in Singapore more than in Munich.

Other critical aspects of effectuation are flexibility, experimentation, and leveraging contingencies. In Silicon Valley, experimenting was described to be common and supported; in Singapore, the market was considered good for experiments. In Munich, entrepreneurs were considered to have a tendency towards testing and iteration but their experiments to be more perfection oriented than the flexible effectuation approach would suggest. Accordingly, flexibility and experimentation may be, like partnerships, facilitated in Silicon Valley and Singapore more than in Munich. Interestingly, the resource orientation that is part of the effectuation approach appeared to be focused on identity (who am I) in Silicon Valley, on competence (what do I know) in Germany, and on contacts (whom do I know) in Singapore.

Causation seemed to be emphasized by the narratives in Munich but discouraged by most of the narratives in Silicon Valley; in Singapore, some narratives seemed to help others to hinder causation (see arrows on the right side in Fig. 2). Causation suggests a focus on competitive analysis. Our findings indicate that, in Singapore, the market is influenced by the government and MNCs, reducing the market competition. In Munich, entrepreneurs were described to care more about perfectioning their product than about the competition in the market. In Silicon Valley, in contrast, there was a strong attention on the competition in the market. Thus, narratives in Silicon Valley seemed to focus on competition more than in Munich and Singapore.

Nevertheless, more important to the causation approach is to make predictions and avoid contingencies. Narratives in Munich were encouraging to decrease the probability of contingencies by a focus on planning and analyses. Also in Singapore, datadriven analyses and conforming to established procedures were perceived to be common as they are required by the government and MNCs. In Silicon Valley, in contrast, the value of contingencies was salient, and the high speed of developments was described to contradict prediction and planning. Thus, planning, prediction, and avoiding contingencies were perceived prevalent in Munich and Singapore but not in Silicon Valley.

In sum, our findings suggest that the narratives about possibilities for networking, exchange, and 
experimentation in Silicon Valley facilitate the flexible and partnerships-oriented approaches of effectuation. Although the competition in the market suggests some causation-based approaches, the high speed of development seems to contradict the predictive logics of causation. In Munich, several factors support an emphasis on causation. Not talking about ideas and avoiding to over promise contradict effectuation, and the reluctance to risk, the perfectionism, the focus on planning, systematics, analyses, and calculations suggest a predominance of causation. Only the tendency towards testing and iteration, stemming from the academic environment, suggests some effectuation logics. In Singapore, the necessity for data-driven analyses, planning to avoid risk, and conforming to rules suggest causation, but the focus on building partnerships and utilizing the possibilities for experimenting in the local market suggests effectuation. Thus, the narratives in the ecosystem in Silicon Valley seem to facilitate effectuation, in Munich causation, and in Singapore a cautious balance of both.

\section{Discussion}

Based on qualitative interviews with serial entrepreneurs, business angels, VCs, and heads of accelerators and incubator programs in three different ecosystems, Silicon Valley, Munich, and Singapore, this paper showed that ecosystems may spark specific narratives which encourage or hinder either effectuation or causation. We identified ecosystem-specific constellations in national culture and attitudes, the market and environment, and resources and networks, and illuminated how the constellation in each ecosystem sparks specific narratives about entrepreneurial attitudes, decisions, and actions, which in turn foster tendencies towards either effectuation or causation. In the following, we discuss how our findings contribute to the literature.

First, we illuminated ecosystem-specific mechanisms influencing entrepreneurs' behaviors and decision-making. Considering that investigations of influence factors in isolation cannot detect reinforcing or counterbalancing mechanisms, the literature on entrepreneurial ecosystems highlighted the importance of considering the wholeness of entrepreneurship in an ecosystem (Anderson et al., 2012; Isenberg, 2010; Roundy et al., 2018; Spigel, 2017; Spigel \& Harrison,
2018). Literature on entrepreneurial ecosystems, however, mainly focused on analyzing the characteristics, development, economic output, and regional outcomes of ecosystems (Wurth et al, 2021) such that the mechanism how an ecosystem influences entrepreneurial outcomes remains unclear. That is one reason why the influence mechanisms in ecosystems have been criticized as "under-theorized" (Roundy \& Fayard, 2019; Spigel \& Harrison, 2018; Wurth et al, 2021). One pathway that has been neglected is the influence of ecosystem characteristics on entrepreneurs' individual behaviors and decision-making.

Our research goes beyond previous analyses of ecosystem influences because we show mechanisms how ecosystem characteristics play together in influencing entrepreneurs' behaviors and decision-making. We uncovered why and how some ecosystems facilitate effectuation and others causation, by considering a wide range of influence factors including the national culture, attitudes, market characteristics, available resources, and networks. Analyzing influence mechanisms in an ecosystem as a whole, and identifying relevant combinations of influence factors, our research indicated how different factors reinforce or counterbalance each other in fostering or hindering either effectuation or causation. This analysis illuminated mechanisms how ecosystem characteristics influence entrepreneurship that were so far unexplored. We hope that our findings inspire future theorizing on how ecosystems influence entrepreneurship.

Second, we introduced differences in factor constellations in entrepreneurial ecosystems as drivers of effectuation and causation. The effectuation literature provides knowledge on outcomes as well as predictors of effectuation and causation (Grégoire \& Cherchem, 2020; Perry et al., 2012). Previous research indicated that entrepreneurs' individual traits (Cannatelli et al., 2019; Michaelis et al., 2020; Liu, 219; Stroe et al., 2018) and experiences (Engel et al., 2013; Frese et al., 2019; Markowska et al., 2018), relations and management approaches in teams (Nguyen et al., 2018; Tryba \& Fletcher, 2019), stages of venture development (Frese et al., 2019), investors (Frese et al., 2019), and networks (Galkina \& Lundgren-Henriksson, 2017; Zhang et al., 2020) influence preferences for either effectuation or causation. That research, however, neglected that these influence factors play together, and this interplay may vary across different 
locations. While previous literature has investigated predictors of effectuation in Western (e.g., Frese et al., 2019; Tryba \& Fletcher, 2019) as well as Eastern (e.g., Zhang et al., 2020) parts of the world, and indicated country differences (Laskovaia et al., 2017; Zhang et al., 2019), our analysis provides more comprehensive knowledge on location differences. Illuminating influence mechanisms at particular locations, our research introduced a new ecosystemfocused perspective on predictors of effectuation and causation. We suggest that the ecosystem-specific interplay of influence factors shapes tendencies towards effectuation and causation. Thus, we suggest future research on effectuation needs to pay more attention on the location where effectuation is studied.

Importantly, our findings do not contradict an influence of individual differences of entrepreneurs. Instead, we argue that influences of individual tendencies, which influence effectuation or causation (e.g., self-control and frugality (Michaelis et al., 2020), types of passion (Cannatelli et al., 2019), and aspirations (Lui, 2019)), are more likely in some ecosystems than in others, e.g., due to the national culture at a particular location and because narratives in ecosystems facilitate or hinder these individual tendencies. Nevertheless, we call for more research to provide a more detailed understanding of how individual and environmental characteristics play together in shaping effectuation and causation.

Third, we suggest considering ecosystem-specific narratives can help to connect the ecosystem and effectuation literature. While the literature on ecosystems and the literature on effectuation developed almost unrelatedly, our findings indicate that reinforced narratives (Roundy \& Bayer, 2019) are one mechanism explaining the connections. Narratives may explain how characteristics of ecosystems influence tendencies towards effectuation and causation. This mechanism highlights connections between findings of the ecosystem literature, which suggest joint influences of the culture, resources, networks, talent, and institutions in entrepreneurial ecosystems (Wurth et al, 2021), and findings of the effectuation literature, which suggest that the culture, attitudes, uncertainty, dynamism, resources, and networks influence tendencies towards effectuation and causation (Björklund \& Krueger, 2016; Frese et al., 2019; Galkina \& Atkova, 2020).
Considering narratives as connectors of ecosystem characteristics and effectuation provides a more comprehensive picture than each of the literatures can provide. To investigate the role of narratives in more detail, future research could draw on institutional theory (North, 1990) and examine in what way narratives, which can be understood as informal institutions in the form of norms, conventions, and codes of behavior, could explain differences in the formation and endurance of regional differences in entrepreneurial activity, especially in settings with similar formal institutions such as rules, laws, and constitutions (Wyrwich et al., 2016).

Finally, by identifying connections of ecosystemspecific narratives with effectuation and causation, we provide insights into the suitability of effectuation and causation in different contexts. While our findings affirm the value of effectuation, especially by increasing speed, flexibility, and networks, causation seems to remain imperative in interactions with the outside world. For instance, causationbased analyses are required for raising money from investors, not only in Munich which is generally focused on causation but also in the other ecosystems; causation-based competitive analysis is considered essential for survival in a highly competitive environment, specifically in Silicon Valley, which is otherwise focused on effectual approaches; and causation-based predictions of market developments appear imperative for internationalization efforts, which is not only relevant in Singapore where the mechanism appeared as particularly influential. Our findings also connect with previous observations of a positive influence of the networking culture in Silicon Valley (Gill \& Larson, 2014) and a negative influence of perfectionism and lack of social trust in Germany (Aly \& Galal-Edeen, 2020) on entrepreneurship. Nevertheless, future research is needed to investigate in how far the factors that influence effectuation in an ecosystem also influence the level of entrepreneurship in an ecosystem.

\subsection{Implications for practice}

In an increasingly globalized world, it is vital to heed local circumstances including differences in the culture, the market, and in the functioning of resource allocation and networks at different locations. Our findings can inform entrepreneurs, VCs, and policy 
makers. Our findings suggest that local ecosystems require specific strategies and have specific success factors. For example, due to the effectuation and partnership focus in Silicon Valley, it appears to be easier than in Munich or Singapore to establish an initial contact or cooperation agreements. Therefore, entrepreneurs in Munich and Singapore need strategies to overcome the barriers to collaboration with established players, whereas entrepreneurs in Silicon Valley need to focus on internal delivery, track actual outcomes of relationships, and focus on long-term commitments. Additionally, in Munich, meeting corporate decision makers is a key milestone because waiting for meetings creates problematically long delays. For entrepreneurs in Germany, collaboration with medium-sized businesses (the "Mittelstand" which is considered the backbone of the German economy) appears as a better fit than collaboration with larger corporates because mediumsized businesses are more likely to have decision-making and innovation processes that are similar to effectual approaches of entrepreneurs. For entrepreneurs in Singapore, key is establishing trust and legitimacy by showing strong commitment in face-to-face meetings, proofs-of-concepts, and references, and establishing profitable long-term relationships even if that means forgoing revenues in the beginning. Furthermore, due to the relevance of causation and avoiding contingencies in Munich, success in Munich is more likely with a pitch that focuses on plans, technical product features, and entrepreneurs' technical expertise. In contrast, in Silicon Valley, it seems to be more important to provide a comprehensive big picture including possibilities for growth, and in Singapore to signal conformity and a strong network to establish legitimacy.

We suggest that entrepreneurs need to carefully balance general best practices and ecosystem-specifics. Despite the universal recognition of its global success, the Silicon Valley type of entrepreneurship may not be optimal under the differing prerequisites of other ecosystems (Whittaker, 2009). Considering the substantial differences, it seems reasonable to focus on native strengths and adjust to (or deliberately work against) local narratives. Still, our findings affirm the general value of effectuation for entrepreneurs, across ecosystems, and indicate that entrepreneurs should not completely avoid causation. Planning and analyses are likely to be required for raising money from investors, competitive analysis for survival in a competitive environment, and predictions of market developments for internationalization efforts, at all locations. Therefore, contrasting ecosystems can help entrepreneurs to choose an ecosystem that best fits their idea and strategy, and can help them to develop strategies for overcoming challenges, avoiding pitfalls, and developing their venture beyond the standard approach that is suggested by the narratives in their ecosystem.

VCs and policy makers who aim to facilitate the functioning of entrepreneurial ecosystems should think about how to leverage strengths and how to counteract problematic mechanisms in an ecosystem. They could, for example, support entrepreneurs in Munich in intensifying their sales and marketing orientation while simultaneously nudging them to think bigger, e.g., by exploiting their reputation for quality products and reliability. Similarly, they could help Singaporean entrepreneurs exploring opportunities for gaining legitimacy and trust in the marketplace while exploiting Singapore's hub position for logistics and infrastructure and the advantages of a multicultural society with a born-global attitude.

\subsection{Limitations and avenues for future research}

Our explorative study built on interviews with entrepreneurship experts across three ecosystems. While this study could identify mechanisms that appeared to be specific for each ecosystem, we could not test causal relationships. Additional survey studies and experiments could show whether the differences in national culture and attitudes, the market, resources, and networks indeed cause the specific narratives, and whether the mechanisms have indeed a causal influence on tendencies towards either effectuation or causation. Although we applied techniques to reduce the likelihood that stereotypes biased our results, we cannot exclude any kind of influence. We built our reasoning on communalities in interview statements, and interpretations during iterations between our data and previous literature. To validate our findings, future research could manipulate ecosystem differences and the perceived prevalence of specific narratives in experiments and/or measure ecosystem characteristics, narratives, and effectuation and causation in surveys. Moreover, future research should investigate the role of individual differences in the mechanisms that we observed.

Furthermore, we focused our analysis on Silicon Valley, Munich, and Singapore. Additional analyses 
are needed to analyze whether the mechanisms that we observed are also evident in other ecosystems. Future research could aim to uncover the ecosystem characteristics of other geographical regions, and their impact on entrepreneurial action. Investigations of young and fast-growing entrepreneurial ecosystems or comparisons of our findings with observations in ecosystems that are less successful would be particularly interesting. We call for more research that considers the influences of ecosystem characteristics.

Moreover, several interesting aspects in our data, which we did not focus on in this analysis, might indicate interesting avenues for future research. For example, we found that whereas in all three ecosystems VCs focus on entrepreneurs' means, as effectuation suggests, VCs tend to focus on entrepreneurs' sales ability in Silicon Valley, technical expertise in Munich, and networks in Singapore. Moreover, we found that the different cultural attributes and attitudes in each ecosystem may lead to different foci of attention and differences in what is valued. Such differences in attention and value focus might imply that some entrepreneurial ideas fit one ecosystem better than others. Future research could investigate what kind of ideas fit which ecosystems and why. Furthermore, we could infer from our analyses that there is a self-reinforcing process in each ecosystem. When entrepreneurs tailor to the specifics in the ecosystem and then become VCs and gatekeepers, they are also likely to focus on those specifics and suggest entrepreneurs to make sure they fit and leverage these specifics. Longitudinal research is needed to better understand such self-reinforcing mechanisms over time (Baker \& Welter, 2020). We hope that our study on effectuation and causation in entrepreneurial ecosystems will encourage further research on the influence of ecosystem specifics on entrepreneurs.

Funding Open access funding provided by Libera Università di Bolzano within the CRUI-CARE Agreement. This research was supported by funding of the Singapore Ministry of Education Social Science Research Thematic Grant under MOE2017-SSRTG-022. Any opinions, findings, and conclusions or recommendations expressed in this material are those of the authors and do not reflect the views of the Singapore Ministry of Education or the Singapore Government.Any opinions, findings, and conclusions or recommendations expressed in this material are those of the authors and do not reflect the views of the Singapore Ministry of Education or the Singapore Government.
Open Access This article is licensed under a Creative Commons Attribution 4.0 International License, which permits use, sharing, adaptation, distribution and reproduction in any medium or format, as long as you give appropriate credit to the original author(s) and the source, provide a link to the Creative Commons licence, and indicate if changes were made. The images or other third party material in this article are included in the article's Creative Commons licence, unless indicated otherwise in a credit line to the material. If material is not included in the article's Creative Commons licence and your intended use is not permitted by statutory regulation or exceeds the permitted use, you will need to obtain permission directly from the copyright holder. To view a copy of this licence, visit http://creativecommons.org/licenses/by/4.0/.

\section{Appendix 1. Information on interviewees and their recruitment}

We chose Silicon Valley, as prototype ecosystem, and Munich and Singapore as equally successful contrasts with a very different culture and history. Note that we did not sample those three ecosystem to contrast effectuation and causation. We identified effectuation and causation as concepts that may help us pinpoint the differences, during the analysis process (see also Appendix 3).

We chose interview partners with exceptional experience in entrepreneurship (see also Table 1 in the paper for specific information on each interviewee). We approached potential interviewees via the personal network of the authors and asked each interviewee whether they can refer us to other interview partners. All our interviewees had substantial experience in founding companies, particularly in building innovative technology companies. We purposefully incorporated individuals with diverse backgrounds and roles. They are either serial entrepreneurs, business angels, venture capitalists, or heads of accelerators or incubator programs. All of them also support novice entrepreneurs such that they are in a gatekeeper position, where they select who gets support and resources. Therefore, their perspective also strengthens and multiplies opinions and behaviors.

In total, we interviewed 43 individuals, several of them twice, in both German and English. Most interviews were conducted personally at the informants' familiar setting and some had to be held via phone due to scheduling restrictions. Participants ranged in age from 26 to 65 years with an average of 47 years. With only three female participants, the study reflects 
the male-dominated nature of the industry. The duration of the individual interviews varied from $40 \mathrm{~min}$ to $1.5 \mathrm{~h}$ with phone interviews tending to be shorter than personally conducted interviews, yielding a total of $43.71 \mathrm{~h}$ of interview material. All interviews were recorded with the permission of the informants and fully transcribed.

\section{Appendix 2. Information on interview questions}

We developed an interview protocol, which we pretested before the first interview. To allow for an open and informal dialog with flexibility to talk about topics that the interviewees bring up, and at the same time ensure that all relevant topics are covered, we followed a protocol with open-ended questions. We intended to capture the interviewees' perspective and minimize our influence on their responses to the interview questions. We began with questions about their background, experience with entrepreneurship in different geographical regions, and the roles they had. Next, we addressed specifics about entrepreneurial processes that they were involved in, asked them to elaborate on underlying drivers and sub-processes, and asked them about ecosystem specifics. We asked interviewees to talk about their general approaches, their opinions, and their observations of what is specific about and typical for entrepreneurship in the ecosystems they are familiar with. Specifically, we asked for:

1. Descriptions of and recommendations for the ecosystems regarding

2. business models, processes, success factors, mistakes, challenges, tools, milestones

3. traits, tastes, personality, experience, capabilities and competencies of entrepreneurs

4. resource acquisition and the role of business plans

5. stakeholders and networks

6. coping with risk and uncertainty

7. dealing with errors and mistakes, the role of adaptation and flexibility

8. Subjective explanations for the specifics and their influence on entrepreneurial activity

9. specifics about the local environment and its influence on entrepreneurship
10. opportunities/strengths, and threats/weaknesses in the ecosystems

11. influences of the specifics about the culture, the people, and the market in the ecosystems

12. match of certain behaviors or opportunities with specific environments

Wherever possible, we triangulated interviewees' statements with additional information from other stakeholders and data that was available online.

\section{Appendix 3. Information on analysis steps}

Our inductive approach (Eisenhardt et al., 2016) allowed us to integrate concepts and mechanisms that were not pre-defined but emerged from the data during the analysis process (Gioia et al., 2013). We iteratively went through the following three phases.

\section{Phase 1}

First, the second and fourth author independently coded all interview data to identify differences and commonalities in interviewees' statements (Gioia et al., 2013). They read all transcripts line by line, marked similarities and differences across interviews, and noted their insights. To increase validity, the first author then again coded the parts of the interview data which were identified as relevant. We compared and contrasted our observations and discussed our interpretations until we reached agreement (Corbin $\&$ Strauss, 2008). The third author was not involved in the data analysis but challenged our emerging findings from an external perspective (Strauss \& Corbin, 1994). We categorized statements by:

- Differences between the entrepreneurial ecosystems that interviewees perceive (e.g., failure is considered a learning experience in Silicon Valley but is stigmatized in Singapore)

- Specifics of an entrepreneurial ecosystem that interviewees perceive (e.g., encouraging of thinking big in Silicon Valley)

- What interviewees consider to be typical attitudes, decisions, and actions of entrepreneurs in an ecosystem (e.g., entrepreneurs in Munich tend to work on their product until they think it is perfect) 
- What interviewees consider to be successful attitudes, decisions, and actions of entrepreneurs in an ecosystem (e.g., showing a lot of logos of wellknown brands in a presentation is in Singapore considered a signal of having legitimacy and good networks)

During these analyses, we found that interviewees reiterated specific narratives which indicate what is considered common, useful, appropriate, and/or successful in their ecosystem, and/or what is encouraged or discouraged; and those narratives were repeatedly suggested to drive tendencies towards specific approaches and logics of entrepreneurs.

\section{Phase 2}

\section{Capturing the data}

Following recommendations for qualitative research (Miles et al., 2014), we iterated between the data and our interpretation as we discussed and explored different versions of data reduction and data display. We created thick descriptions of ecosystems and created tables that ordered statements and codes by overarching concepts (Eisenhardt et al., 2016; Miles et al., 2014). Different visualizations helped us drawing conclusions in a collaborative process (Miles et al., 2014). For example, we created tables with particularly striking quotes/insights for each ecosystem, which we ordered by different levels of analysis, and by links to the logics of effectuation and causation; we also created different figures such as concept networks illustrating links and mechanisms that were described by interviewees. Creating different visualizations helped us drawing conclusions in a collaborative process.

\section{Structuring insights and labelling}

We extracted repeatedly mentioned ecosystem constellations. Due to similarities in statements referring to perceived influence factors related to the national culture and attitudes, market characteristics, available resources and networks, we decided to group these statements based on these categories. Moreover, we substantiated and labelled the identified narratives. The first author developed suggestions for labels which we then collectively challenged and adapted until we agreed that they reflect the data, pinpoint the narratives, and are clear and understandable to outsiders. In the final manuscript we used these labels and refer to them with the letters (a) "be confident, think big" to (o) "keep ideas alive."

\section{Understanding mechanisms}

We then analyzed links between the differences and specifics of the ecosystem constellations, and the narratives (a)-(o) about typical and successful entrepreneurial attitudes, decisions, and actions. We found that the narratives were repeatedly suggested to drive tendencies towards specific approaches and logics of entrepreneurs. We concluded from our observations and interpretations that the narratives may constitute pathways via which ecosystem constellations drive specific tendencies in entrepreneurial behavior.

\section{Phase 3}

To explore how narratives may shape tendencies in entrepreneurial behavior, we went back and forth between knowledge from previous research and the observations in our data (Miles \& Huberman, 1994). Iterating between the data and the literature helped us to get an in-depth understanding about the links and connections among the concepts that we had identified. In this process, we found communalities in how interviewees described influence mechanisms in each ecosystem. These communalities indicated that there could be locale-specific influence mechanisms. We compared our findings to mechanisms that were described in the literature to identify overlaps, contradictions, qualifications, and refinements (Miles et al., 2014). During our comparison with and integration of theoretical perspectives and knowledge from previous research, we also investigated links between the narratives and effectuation and causation (Sarasvathy, 2001). That was when we realized that the concepts effectuation and causation can help us pinpoint the most striking differences between the ecosystems. The narratives about typical and successful entrepreneurial attitudes, decisions, and actions appeared to be linked to effectuation and causation, such that the presence of such narratives seemed to be very likely to create and reinforce tendencies towards either the effectuation or the causation approach. Although we 
could not infer or empirically test causality with our research design, we could identify conceptual links between the narratives and tendencies towards either effectuation or causation. Our reasoning is based on a combination of arguments of our interviewees and arguments in the literature. In an iterative approach, we repeatedly discussed the connections that we drew in the author team, challenged each other's reasoning, and refined visualizations of the connections.

Finally, we visualized the links between the narratives and effectuation and causation and concluded that ecosystem specific mechanisms seem to create and reinforce tendencies towards either effectuation or causation. Our final analysis aimed at illuminating the whole mechanism, i.e., linking the differences between the three entrepreneurial ecosystems with the narratives about attitudes, decisions, and actions in each ecosystem, and showing which narratives drive tendencies towards either effectuation or causation. Figures 1 and 2 depict the outcome of this process. We describe the mechanism in that we group and order by:

(1) Differences and specifics of the ecosystem constellations (i.e., the ecosystem constellations)

(2) The entrepreneurial attitudes, decisions, and actions that were considered to be common, appropriate, or successful (the narratives referred to as categories (a) to (o) in the text, figures and tables in the paper)

(3) The links of the narratives to effectuation and causation (Sarasvathy, 2001)

\section{References}

Aldrich, H. E., \& Yang, T. (2014). How do entrepreneurs know what to do? Learning and organizing in new ventures. Journal of Evolutionary Economics, 24(1), 59-82. https://doi.org/10.1007/s00191-013-0320-X

Alvarez, S. A., \& Barney, J. B. (2005). How do entrepreneurs organize firms under conditions of uncertainty? Journal of Management, 31(5), 776-793. https://doi.org/10.1177/ 0149206305279486

Aly, M., \& Galal-Edeen, G. (2020). Why is Germany less entrepreneurial? A behavioral reasoning perspective. The Journal of Technology Transfer, 1-41. https://doi.org/10. 1007/s10961-020-09823-4

An, W., Rüling, C. C., Zheng, X., \& Zhang, J. (2020). Configurations of effectuation, causation, and bricolage:
Implications for firm growth paths. Small Business Economics, 54, 843-864. https://doi.org/10.1007/ s11187-019-00155-8

Anderson, A. R., Drakopoulou Dodd, S., \& Jack, S. L. (2012). Entrepreneurship as connecting: Some implications for theorising and practice. Management Decision, 50(5), 958-971. https://doi.org/10.1108/00251741211227708

Audretsch, D. B., \& Link, A. N. (2019). Embracing an entrepreneurial ecosystem: An analysis of the governance of research joint ventures. Small Business Economics, 52(2), 429-436. https://doi.org/10.1007/s11187-017-9953-8

Baker, T., \& Welter, F. (2020). Contextualizing Entrepreneurship Theory. Routledge.

Baumol, W. J., \& Strom, R. J. (2008). Entrepreneurship and economic growth. Strategic Entrepreneurship Journal, 1(3-4), 233-237. https://doi.org/10.1002/sej.26

Berends, H., Jelinek, M., Reymen, I., \& Stultiëns, R. (2014). Product innovation processes in small firms: Combining entrepreneurial effectuation and managerial causation. Journal of Product Innovation Management, 31(3), 616635. https://doi.org/10.1111/jpim.12117

Bertoni, F., Colombo, M. G., \& Quas, A. (2019). The role of governmental venture capital in the venture capital ecosystem: An organizational ecology perspective. Entrepreneurship Theory and Practice, 43(3), 611-628. https:// doi.org/10.1177/1042258717735303

Bhawe, N., \& Zahra, S. A. (2019). Inducing heterogeneity in local entrepreneurial ecosystems: The role of MNEs. Small Business Economics, 52(2), 437-454. https://doi. org/10.1007/s11187-017-9954-7

Björklund, T. A., \& Krueger, N. F. (2016). Generating resources through co-evolution of entrepreneurs and ecosystems. Journal of Enterprising Communities: People and Places in the Global Economy, 10(4), 477-498. https://doi.org/10.1108/JEC-10-2016-063

Bosma, N., Hill, S., Ionescu-Somers, A., Kelley, D., Levie, J., \& Tarnawa, A. (2020). Global Entrepreneurship Monitor 2019/2020 Global Report. Global Entrepreneurship Research Association.

Bosma, N., \& Kelley, D. (2019). Global entrepreneurship monitor 2018/2019 global report. Global Entrepreneurship Research Association.

Brettel, M., Mauer, R., Engelen, A., \& Küpper, D. (2012). Corporate effectuation: Entrepreneurial action and its impact on R\&D project performance. Journal of Business Venturing, 27(2), 167-184. https://doi.org/10.1016/j.jbusv ent.2011.01.001

Brinckmann, J., Grichnik, D., \& Kapsa, D. (2010). Should entrepreneurs plan or just storm the castle? A meta-analysis on contextual factors impacting the business planning-performance relationship in small firms. Journal of Business Venturing, 25(1), 24-40. https://doi.org/10. 1016/j.jbusvent.2008.10.007

Busenitz, L. W., \& Barney, J. B. (1997). Differences between entrepreneurs and managers in large organizations: Biases and heuristics in strategic decision-making. Journal of Business Venturing, 12(1), 9-30. https://doi.org/ 10.1016/S0883-9026(96)00003-1

Cannatelli, B., Pedrini, M., \& Braun, M. (2019). Individuallevel antecedents of the entrepreneurial approach: The role of different types of passion in the Italian craft 
brewing industry. International Entrepreneurship and Management Journal, 15(4), 1193-1219. https://doi.org/ 10.1007/s11365-019-00585-6

Chandler, G. N., DeTienne, D. R., McKelvie, A., \& Mumford, T. V. (2011). Causation and effectuation processes: A validation study. Journal of Business Venturing, 26(3), 375-390. https://doi.org/10.1016/j.jbusvent.2009.10.006

Chernyshenko, O. S., Uy, M. A., Jiang, W., Ho, M. H. R., Lee, S. P., Chan, K. Y., \& Yu, K. Y. T. (2015). Global Entrepreneurship Monitor 2014 Singapore Report. Nanyang Technological University.

Clough, D. R., Fang, T. P., Vissa, B., \& Wu, A. (2019). Turning lead into gold: How do entrepreneurs mobilize resources to exploit opportunities? Academy of Management Annals, 13(1), 240-271. https://doi.org/10.5465/ annals.2016.0132

Colombo, M. G., Dagnino, G. B., Lehmann, E. E., \& Salmador, M. (2019). The governance of entrepreneurial ecosystems. Small Business Economics, 52(2), 419-428. https://doi.org/10.1007/s11187-017-9952-9

Corbin, J. M., \& Strauss, A. L. (2008). Basics of qualitative research: Techniques and procedures for developing grounded theory. Sage.

Cui, L., Su, S.-I.I., Feng, Y., \& Hertz, S. (2019). Causal or effectual? Dynamics of decision making logics in servitization. Industrial Marketing Management, 82, 15-26. https://doi.org/10.1016/j.indmarman.2019.03.013

De Clercq, D., \& Voronov, M. (2009). The role of cultural and symbolic capital in entrepreneurs' ability to meet expectations about conformity and innovation. Journal of Small Business Management, 47(3), 398-420. https://doi. org/10.1111/j.1540-627X.2009.00276.x

de Vasconcelos Gomes, L. A., Salerno, M. S., Phaal, R., \& Probert, D. R. (2018). How entrepreneurs manage collective uncertainties in innovation ecosystems. Technological Forecasting and Social Change, 128, 164-185. https://doi.org/10.1016/j.techfore.2017.11.016

Eisenhardt, K. M., Graebner, M. E., \& Sonenshein, S. (2016). Grand challenges and inductive methods: Rigor without rigor mortis. Academy of Management Journal, 59(4), 1113-1123. https://doi.org/10.5465/amj.2016.4004

Engelen, A., Heinemann, F., \& Brettel, M. (2009). Crosscultural entrepreneurship research: Current status and framework for future studies. Journal of International Entrepreneurship, 7, 163-189. https://doi.org/10.1007/ s10843-008-0035-5

Engel, Y., Kleijn, E., \& Khapova, S. (2013). Career as antecedent of entrepreneurial decision-making. Academy of Management Proceedings, 1, 10169. https://doi.org/10. 5465/ambpp.2013.125

Engel, Y., Dimitrova, N. G., Khapova, S. N., \& Elfring, T. (2014). Uncertain but able: Entrepreneurial self-efficacy and novices' use of expert decision-logic under uncertainty. Journal of Business Venturing Insights, 1, 12-17. https://doi.org/10.1016/j.jbvi.2014.09.002

EstradaCruz, M., VerdúJover, A. J., \& GómezGras, J. M. (2019). The influence of culture on the relationship between the entrepreneur's social identity and decision-making: Effectual and causal logic. BRQ Business Research Quarterly, 22(4), 226-244. https://doi.org/10. 1016/j.brq.2018.10.002
Estrin, S., Korosteleva, J., \& Mickiewicz, T. (2013). Which institutions encourage entrepreneurial growth aspirations? Journal of Business Venturing, 28(4), 564-580. https://doi.org/10.1016/j.jbusvent.2012.05.001

Fisher, G., Kotha, S., \& Lahiri, A. (2016). Changing with the times: An integrated view of identity, legitimacy, and new venture life cycles. Academy of Management Review, 41(3), 383-409. https://doi.org/10.5465/amr. 2013.0496

Frese, T., Geiger, I., \& Dost, F. (2019). An empirical investigation of determinants of effectual and causal decision logics in online and high-tech start-up firms. Small Business Economics, 54, 641-664. https://doi.org/10. 1007/s11187-019-00147-8

Fritsch, M., \& Schroeter, A. (2011). Why does the effect of new business formation differ across regions? Small Business Economics, 36(4), 383-400. https://doi.org/ 10.1007/s11187-009-9256-9

Fritsch, M., \& Storey, D. J. (2014). Entrepreneurship in a regional context: Historical roots, recent developments and future challenges. Routledge.

Gabrielsson, J., \& Politis, D. (2011). Career motives and entrepreneurial decision-making: Examining preferences for causal and effectual logics in the early stage of new ventures. Small Business Economics, 36(3), 281-298. https://doi.org/10.1007/s11187-009-9217-3

Galkina, T., \& Atkova, I. (2020). Effectual Networks as Complex Adaptive Systems: Exploring Dynamic and Structural Factors of Emergence. Entrepreneurship Theory and Practice, 44(5), 964-995. https://doi.org/10.1177/ 1042258719879670

Galkina, T., \& Lundgren-Henriksson, E.-L. (2017). Coopetition as an entrepreneurial process: Interplay of causation and effectuation. Industrial Marketing Management, 67, 158-173. https://doi.org/10.1016/j.indma rman.2017.09.004

Ghio, N., Guerini, M., \& Rossi-Lamastra, C. (2019). The creation of high-tech ventures in entrepreneurial ecosystems: Exploring the interactions among university knowledge, cooperative banks, and individual attitudes. Small Business Economics, 52(2), 523-543. https://doi. org/10.1007/s11187-017-9958-3

Gill, R., \& Larson, G. S. (2014). Making the ideal (local) entrepreneur: Place and the regional development of high-tech entrepreneurial identity. Human Relations, 67(5), 519-542. https://doi.org/10.1177/0018726713 496829

Gioia, D. A., Corley, K. G., \& Hamilton, A. L. (2013). Seeking qualitative rigor in inductive research: Notes on the Gioia methodology. Organizational Research Methods, 16(1), 15-31. https://doi.org/10.1177/1094428112452151

Glaser, B., \& Strauss, A. (1968). The discovery of grounded theory. Weidenfeld \& Nicolson.

Grégoire, D. A., \& Cherchem, N. (2020). A structured literature review and suggestions for future effectuation research. Small Business Economics, 54(3), 621-639. https://doi.org/10.1007/s11187-019-00158-5

Harms, R., \& Schiele, H. (2012). Antecedents and consequences of effectuation and causation in the international new venture creation process. Journal of International 
Entrepreneurship, 10(2), 95-116. https://doi.org/10. 1007/s10843-012-0089-2

Hayton, J. C., George, G., \& Zahra, S. A. (2002). National culture and entrepreneurship: A review of behavioral research. Entrepreneurship Theory and Practice, 26(4), 33-52. https://doi.org/10.1177/104225870202600403

Henninger, P., Brem, A., Giones, F., Bican, P. M., \& Wimschneider, C. (2020). Effectuation vs. causation: Can established firms use start-up decision-making principles to stay innovative? International Journal of Innovation Management, 24(01), 2050002. https://doi.org/ 10.1142/S1363919620500024

Hoang, H., \& Antoncic, B. (2003). Network-based research in entrepreneurship: A critical review. Journal of Business Venturing, 18(2), 165-187. https://doi.org/10. 1016/S0883-9026(02)00081-2

House, R. J., Hanges, P. J., Javidan, M., Dorfman, P. W., \& Gupta, V. (Eds.). (2004). Culture, leadership, and organizations: The GLOBE study of 62 societies. Sage publications.

Isenberg, D. J. (2010). How to Start an Entrepreneurial Revolution. Harvard Business Review. https://hbr.org/2010/ 06/the-big-idea-how-to-start-an-entrepreneurial-revol ution

Isenberg, D. J. (2016). Applying the ecosystem metaphor to entrepreneurship: Uses and abuses. The Antitrust Bulletin, 61(4), 564-573. https://doi.org/10.1177/0003603X16 676162

Johansson, A., \& McKelvie, A. (2012). Unpacking the antecedents of effectuation and causation in a corporate context. Frontiers of Entrepreneurship Research, Paper presented at the Babson College Entrepreneurship Research Conference

Klandt, H. (2004). Entrepreneurship Education and Research in German-Speaking Europe. Academy of Management Learning \& Education, 3(3), 293-301. https://doi.org/10. 5465/amle.2004.14242226

Kujala, I., \& Tornroos, J.-A. (2018). Internationalizing through networks from emerging to developed markets with a case study from Ghana to the USA. Industrial Marketing Management, 69, 98-109. https://doi.org/10.1016/j. indmarman.2018.01.015

Laskovaia, A., Shirokova, G., \& Morris, M. H. (2017). National culture, effectuation, and new venture performance: Global evidence from student entrepreneurs. Small Business Economics, 49(3), 687-709. https://doi.org/10.1007/ s11187-017-9852-z

Lee, T., \& Lim, D. (2004). The economics and politics of'creativity'in Singapore. Australian Journal of Communication, 31(2), 149. https://doi.org/10.3316/ielapa. 200411991

Liu, Y. T. (2019). Exploring the role of original aspiration in effectuation tendency. International Entrepreneurship and Management Journal, 15(3), 977-1016. https://doi. org/10.1007/s11365-019-00575-8

Maresova, P., Stemberkova, R., \& Fadeyi, O. (2019). Models, processes, and roles of universities in technology transfer management: A systematic review. Administrative Sciences, 9(3), 67. https://doi.org/10.3390/admsci9030067

Markowska, M., Grichnik, D., Brinckmann, J., \& Kapsa, D. (2018). Strategic orientations of nascent entrepreneurs:
Antecedents of prediction and risk orientation. Small Business Economics, 53, 859-878. https://doi.org/10. 1007/s11187-018-0107-4

Mauer, R., Wuebker, R., Schlüter, J., \& Brettel, M. (2018). Prediction and control: An agent-based simulation of search processes in the entrepreneurial problem space. Strategic Entrepreneurship Journal, 12(2), 237-260. https://doi. org/10.1002/sej.1271

Maxwell, J. A. (2012). Qualitative research design: An interactive approach (Vol. 41). Sage publications.

McMullen, J. S., \& Shepherd, D. A. (2006). Entrepreneurial Action and the Role of Uncertainty in the Theory of the Entrepreneur. Academy of Management Review, 31(1), 132-152. https://doi.org/10.5465/amr.2006.19379628

Michaelis, T. L., Carr, J. C., Scheaf, D. J., \& Pollack, J. M. (2020). The frugal entrepreneur: A self-regulatory perspective of resourceful entrepreneurial behavior. Journal of Business Venturing, 35(4), 105969. https://doi.org/10. 1016/j.jbusvent.2019.105969

Miles, M. B., \& Huberman, A. M. (1994). Qualitative data analysis: An expanded sourcebook (2nd ed.). Sage Publications, Inc.

Miles, M. B., Huberman, A. M., \& Saldaña, J. (2014). Qualitative data analysis: A methods sourcebook. Sage publications.

Moser, K. J., Tumasjan, A., \& Welpe, I. M. (2017). Small but attractive: Dimensions of new venture employer attractiveness and the moderating role of applicants' entrepreneurial behaviors. Journal of Business Venturing, 32(5), 588-610. https://doi.org/10.1016/j.jbusvent.2017.05.001

Motoyama, Y., \& Knowlton, K. (2016). From resource munificence to ecosystem integration: The case of government sponsorship in St Louis. Entrepreneurship \& Regional Development, 28(5-6), 448-470. https://doi.org/10.1080/ 08985626.2016 .1186749

North, D. C. (1990). Institutions, institutional change and economic performance. Cambridge University Press.

Nambisan, S., \& Baron, R. A. (2013). Entrepreneurship in innovation ecosystems: Entrepreneurs' self-regulatory processes and their implications for new venture success. Entrepreneurship Theory and Practice, 37(5), 10711097. https://doi.org/10.1111/j.1540-6520.2012.00519.x

Nelson, R., \& Lima, E. (2019). Effectuations, social bricolage and causation in the response to a natural disaster. Small Business Economics, 54, 721-750. https://doi.org/10. 1007/s11187-019-00150-z

Nguyen, N. M., Killen, C. P., Kock, A., \& Gemünden, H. G. (2018). The use of effectuation in projects: The influence of business case control, portfolio monitoring intensity and project innovativeness. International Journal of Project Management, 36(8), 1054-1067. https://doi.org/10. 1016/j.ijproman.2018.08.005

Peng, M. W., Yamakawa, Y., \& Lee, S. (2010). Bankruptcy laws and entrepreneur- Friendliness. Entrepreneurship Theory and Practice, 34(3), 517-530. https://doi.org/10. 1111/j.1540-6520.2009.00350.x

Perry, J. T., Chandler, G. N., \& Markova, G. (2012). Entrepreneurial effectuation: A review and suggestions for future research. Entrepreneurship Theory and Practice, 36(4), 837-861. https://doi.org/10.1111/j.1540-6520.2010. 00435.x 
Powell, W. W., Koput, K. W., Bowie, J. I., \& Smith-Doerr, L. (2002). The spatial clustering of science and capital: Accounting for biotech firm-venture capital relationships. Regional Studies, 36(3), 291-305. https://doi.org/10. $1080 / 00343400220122089$

Read, S., \& Sarasvathy, S. D. (2005). Knowing what to do and doing what you know: Effectuation as a form of entrepreneurial expertise. The Journal of Private Equity, 9(1), 45-62. https://doi.org/10.3905/jpe.2005. 605370

Read, S., Song, M., \& Smit, W. (2009). A meta-analytic review of effectuation and venture performance. Journal of Business Venturing, 24(6), 573-587. https://doi.org/10. 1016/j.jbusvent.2008.02.005

Reymen, I. M., Andries, P., Berends, H., Mauer, R., Stephan, U., \& Van Burg, E. (2015). Understanding dynamics of strategic decision making in venture creation: A process study of effectuation and causation. Strategic Entrepreneurship Journal, 9(4), 351-379. https://doi.org/10.1002/ sej. 1201

Roach, D. C., Ryman, J. A., \& Makani, J. (2016). Effectuation, innovation and performance in SMEs: An empirical study. European Journal of Innovation Management, 19(2), 214-238. https://doi.org/10.1108/ EJIM-12-2014-0119

Roundy, P. T., \& Bayer, M. A. (2019). Entrepreneurial ecosystem narratives and the micro-foundations of regional entrepreneurship. The International Journal of Entrepreneurship and Innovation, 20(3), 194-208. https://doi.org/ $10.1177 / 1465750318808426$

Roundy, P. T., Bradshaw, M., \& Brockman, B. K. (2018). The emergence of entrepreneurial ecosystems: A complex adaptive systems approach. Journal of Business Research, 86, 1-10. https://doi.org/10.1016/j.jbusres. 2018.01.032

Roundy, P. T., \& Fayard, D. (2019). Dynamic capabilities and entrepreneurial ecosystems: The micro-foundations of regional entrepreneurship. The Journal of Entrepreneurship, 28(1), 94-120. https://doi.org/10.1177/0971355718 810296

Sarasvathy, S. D. (2001). Causation and effectuation: Toward a theoretical shift from economic inevitability to entrepreneurial contingency. Academy of Management Review, 26(2), 243-263. https://doi.org/10.5465/amr.2001.43780 20

Sarasvathy, S. D. (2009). Effectuation: Elements of entrepreneurial expertise. Edward Elgar Publishing.

Schönenberger, H. (2014). Germany: High-tech region Munich generating the next wave of scalable startups. In J. S. Engel (Ed.), Global Clusters of Innovation (pp. 95-119). Edward Elgar Publishing. https://doi.org/10.4337/97817 83470839.00012

Shane, S. (1993). Cultural influences on national rates of innovation. Journal of Business Venturing, 8(1), 59-73. https://doi.org/10.1016/0883-9026(93)90011-S

Shankar, R. K., \& Shepherd, D. A. (2019). Accelerating strategic fit or venture emergence: Different paths adopted by corporate accelerators. Journal of Business Venturing, 34(5), 105886. https://doi.org/10.1016/j.jbusvent.2018. 06.004
Smolka, K. M., Verheul, I., Burmeister-Lamp, K., \& Heugens, P. P. (2018). Get it together! Synergistic effects of causal and effectual decision-making logics on venture performance. Entrepreneurship Theory and Practice, 42(4), 571-604. https://doi.org/10.1177/1042258718783429

Spigel, B. (2017). The relational organization of entrepreneurial ecosystems. Entrepreneurship Theory and Practice, 41(1), 49-72. https://doi.org/10.1111/etap. 12167

Spigel, B., \& Harrison, R. (2018). Toward a process theory of entrepreneurial ecosystems. Strategic Entrepreneurship Journal, 12(1), 151-168. https://doi.org/10.1002/ sej. 1268

Stephan, U., \& Uhlaner, L. M. (2010). Performance-based vs socially supportive culture: A cross-national study of descriptive norms and entrepreneurship. Journal of International Business Studies, 41, 1347-1364. https:// doi.org/10.1057/jibs.2010.14

Sternberg, R., \& Litzenberger, T. (2004). Regional clusters in Germany-Their geography and their relevance for entrepreneurial activities. European Planning Studies, 12(6), 767-791. https://doi.org/10.1080/0965431042000251855

Strauss, A., \& Corbin, J. (1994). Grounded theory methodology. In N. K. Denzin \& Y. S. Lincoln (Eds.), Handbook of qualitative research (pp. 273-285). Sage.

Stroe, S., Parida, V., \& Wincent, J. (2018). Effectuation or causation: An fsQCA analysis of entrepreneurial passion, risk perception, and self-efficacy. Journal of Business Research, 89, 265-272. https://doi.org/10.1016/j.jbusres. 2018.01.035

Stuart, T., \& Sorenson, O. (2003). The geography of opportunity: Spatial heterogeneity in founding rates and the performance of biotechnology firms. Research Policy, 32(2), 229-253. https://doi.org/10.1016/S0048-7333(02) 00098-7

Tan, K. P. (2003). Sexing up Singapore. International Journal of Cultural Studies, 6(4), 403-423. https://doi.org/10. 1177/136787790364002

Tryba, A., \& Fletcher, D. (2019). How shared pre-start-up moments of transition and cognitions contextualize effectual and causal decisions in entrepreneurial teams. Small Business Economics, 54, 665-688. https://doi.org/10. 1007/s11187-019-00148-7

Tsai, W.M.-H., MacMillan, I. C., \& Low, M. B. (1991). Effects of strategy and environment on corporate venture success in industrial markets. Journal of Business Venturing, 6(1), 9-28. https://doi.org/10.1016/0883-9026(91) 90003-V

Welter, C., \& Kim, S. (2018). Effectuation under risk and uncertainty: A simulation model. Journal of Business Venturing, 33(1), 100-116. https://doi.org/10.1016/j. jbusvent.2017.11.005

Wiltbank, R., Read, S., Dew, N., \& Sarasvathy, S. D. (2009). Prediction and control under uncertainty: Outcomes in angel investing. Journal of Business Venturing, 24(2), 116-133. https://doi.org/10.1016/j.jbusvent.2007.11.004

Xavier, S. R., Sidin, S. M., Guelich, U., \& Nawangpalupi, C. (2016). ASEAN Regional Entrepreneurship Report 2015/2016. Universiti Tun Abdul Razak, Jalan Tangsi, Kuala Lumpur. http://hdl.handle.net/10625/56932 
Whittaker, D. H. 2009. Comparative entrepreneurship: The UK, Japan, and the Shadow of Silicon Valley: The UK, Japan, and the Shadow of Silicon Valley, OUP Oxford

Wolfe, M. T., \& Shepherd, D. A. (2015). "Bouncing back" from a loss: Entrepreneurial orientation, emotions, and failure narratives. Entrepreneurship Theory and Practice, 39(3), 675-700. https://doi.org/10.1111/etap.12057

Wurth, B., Stam, E., \& Spigel, B. (2021). Toward an entrepreneurial ecosystem research program. Entrepreneurship Theory and Practice. https://doi.org/10.1177/10422 58721998948

Wyrwich, M., Stuetzer, M., \& Sternberg, R. (2016). Entrepreneurial role models, fear of failure, and institutional approval of entrepreneurship: A tale of two regions. Small Business Economics, 46(3), 467-492. https://doi. org/10.1007/s11187-015-9695-4
Zhang, Y., Cui, L., Zhang, G., Sarasvathy, S., \& Anusha, R. (2019). An exploratory study of antecedents of entrepreneurial decision-making logics: The role of self-efficacy, optimism, and perspective taking. Emerging Markets Finance and Trade, 55(4), 781-794. https://doi.org/10. 1080/1540496X.2018.1478283

Zhang, W., Zhao, W., Gao, Y., \& Xiao, Z. (2020). How do managerial ties influence the effectuation and causation of entrepreneurship in China? The role of entrepreneurs' cognitive bias. Asia Pacific Business Review, 26(5), 613-641. https://doi.org/10.1080/13602381.2020.17655 37

Publisher's note Springer Nature remains neutral with regard to jurisdictional claims in published maps and institutional affiliations. 